\title{
IMPACTO DO MANEJO DE RESÍDUOS ORGÂNICOS DURANTE A REFORMA DE PLANTIOS DE EUCALIPTO SOBRE INDICADORES DE QUALIDADE DO SOLO ${ }^{(1)}$
}

\author{
Guilherme Montandon Chaer $^{(2)}$ \& Marcos Rogério Tótola ${ }^{(3)}$
}

\begin{abstract}
RESUMO
O uso agrícola do solo causa alterações em suas características físicas, químicas e microbiológicas. A conseqüência dessas alterações pode ser a perda da qualidade do solo, o que compromete a sustentabilidade do uso desse recurso. A análise de indicadores bioquímicos e microbiológicos de qualidade do solo é relevante para monitorar mudanças na qualidade do solo e no desempenho de suas funções-chave, como a capacidade de ciclar e armazenar nutrientes. Neste estudo, avaliaram-se indicadores químicos, físicos e microbiológicos do solo em plantios de eucalipto 5,5 anos após terem sido submetidos a diferentes métodos de manejo durante a fase de reforma do povoamento. A avaliação baseou-se na determinação de 18 atributos físicos e químicos, além de 12 outros de caráter bioquímico ou microbiológico, os quais foram adotados como indicadores da qualidade do solo. Os indicadores bioquímicos e microbiológicos mostraram-se mais sensíveis para avaliar mudanças qualitativas no solo devidas ao manejo, quando comparados com os químicos ou físicos. O maior distúrbio causado pelos tratamentos em que houve remoção ou queima do material orgânico da superfície do solo foi evidenciado pelos maiores valores de $q \mathrm{CO}_{2}$ e menores valores de $q \mathrm{MIC}$ na camada superior do solo $(0$ a $5 \mathrm{~cm})$. A análise de componentes principais permitiu visualizar as semelhanças entre as áreas com base em todas as variáveis analisadas. A área de vegetação natural de mata secundária, usada como referência de qualidade do solo, foi a que apresentou a maior distância gráfica das demais áreas, demonstrando que a introdução da monocultura do eucalipto modifica a qualidade do solo estudado. A qualidade do solo da área de eucalipto onde não se efetuou o corte das
\end{abstract}

\footnotetext{
(1) Parte da Tese de Mestrado do primeiro autor apresentada ao Curso de Pós-Graduação em Microbiologia Agrícola da Universidade Federal de Viçosa - UFV. Recebido para publicação em setembro de 2003 e aprovado em julho de 2007.

${ }^{(2)}$ Pesquisador do Centro Nacional de Pesquisa em Agrobiologia - CNPAB/Embrapa. CEP 23890-000 Seropédica (RJ). E-mail: gchaer@cnpab.embrapa.br

${ }^{(3)}$ Departamento de Microbiologia, Universidade Federal de Viçosa - UFV. CEP 36570-000 Viçosa (MG). E-mail: totola@ufv.br
} 
árvores no primeiro ciclo (povoamento com 11 anos de idade) obteve a maior aproximação da área de vegetação natural, seguindo-se os solos sob eucalipto submetido a manejos que priorizaram a conservação dos resíduos orgânicos por ocasião da reforma do povoamento. Contrariamente, as áreas onde ocorreu a remoção ou a queima do material orgânico da superfície do solo foram as que mais se distanciaram da área de referência. Esses resultados demonstram que o sistema de manejo adotado na reforma dos povoamentos de eucalipto analisados influencia, em médio prazo, o potencial dos solos de estocar e ciclar nutrientes por meio da biomassa microbiana e das atividades bioquímicas ligadas a ela. A maior aproximação entre a área com vegetação nativa e a de eucalipto com 11 anos leva a supor que ciclos mais longos nas florestas de eucalipto, contrastando com o padrão atualmente em uso no Brasil (cerca de sete anos), pode ser relevante para se manter a sustentabilidade da atividade florestal em longo prazo, a despeito de uma menor produtividade média anual. Nesse caso, a opção pela produtividade de curto ou médio prazo, ou pela sustentabilidade do uso do solo, com a conseqüente manutenção da sua qualidade para as gerações futuras, poderá ser repensada a partir dos dados aqui apresentados.

Termos de indexação: manejo florestal, sustentabilidade, biomassa microbiana, enzimas do solo.

\title{
SUMMARY: IMPACTOFORGANICRESIDUEMANAGEMENTONSOIL QUALITY INDICATORS DURING REPLANTING OF EUCALYPT STANDS
}

\begin{abstract}
Agricultural soil use induces changes in soil physical, chemical, and microbiological characteristics. These changes can eventually lead to a loss of soil quality and a consequent reduction in plant growth and productivity. The analysis of biochemical and microbiological soil quality indicators is relevant to monitor changes in soil quality and in the performance of key soil functions, such as the capacity of nutrient cycling and storage. This study reports on physical, chemical, and biochemical/microbiological quality indicators of soil under eucalyptus plantation, evaluated 5.5 years after the site had undergone different management practices during stand replanting. Evaluations were based on the determination of 18 physical or chemical besides 12 biochemical or microbiological attributes that are considered soil quality indicators. The microbiological and biochemical attributes proved more adequate than the chemical or physical indicators to detect soil quality changes due to management. The greatest disturbance caused by the removal or burning of organic material on the soil surface was evidenced by the higher $\mathrm{q} \mathrm{CO}_{2}$ and lower $\mathrm{q} M I C$ in the upper soil layer ( 0 to $5 \mathrm{~cm}$ ). The principal component analysis underlying the graphical representation demonstrated that soil under secondary forest, taken as reference for soil quality, was very distant from that under eucalyptus, demonstrating that the introduction of eucalyptus monoculture causes significant changes in soil quality. The soil quality of a eucalyptus stand left unharvested after the first normal seven years cycle (11 year-old stand) was the closest to the area with native forest, followed by the soils under eucalyptus subjected to management systems that prioritized organic residue conservation during stand replanting. Contrarily, areas from which the organic material at the soil surface was removed or burned appeared very distant from the reference area. Our results show that the management system adopted during eucalyptus stand replanting influenced, in the medium term, the potential of soils to store and cycle nutrients via microbial biomass and associated biochemical activities. The fact that the 11 years old eucalyptus stand was closest to the reference area may suggest that the adoption of longer cycles for eucalyptus plantations, contrasting with the actual model of short rotation eucalyptus forests in Brazil (about seven years), is relevant to maintain soil sustainability for eucalyptus production in the long run, in spite of the lower mean annual productivity. In this case, the option for a higher productivity in the short and medium term, or for the sustainability of soil use, with the consequent maintenance of its quality for the future generations, should be reevaluated from the data presented here.
\end{abstract}

Index terms: forest management, sustainability, microbial biomass, soil enzymes. 


\section{INTRODUÇÃO}

É crescente a preocupação das empresas do setor florestal em adotar práticas de manejo ambientalmente saudáveis, que garantam a sustentabilidade da produção florestal. Considerando o solo como um importante componente relacionado à produção de madeira, pois é ele o responsável pelo suprimento de água e de nutrientes para as plantas, a conservação ou a melhoria da sua qualidade é vital para sustentação dessa atividade produtiva. A sustentabilidade da atividade florestal está, dessa forma, diretamente relacionada à conservação do solo.

Apesar de as práticas de manejo florestal serem baseadas nas melhores informações e experiências disponíveis no setor, em muitas situações, o principal critério utilizado para defini-las é a sua relação com a produtividade. Esse critério pode ser considerado inadequado, uma vez que a produtividade é influenciada também por fatores que independem do solo, como clima, genótipo ou desastres naturais (ex.: fogo, pragas, doenças) (Kelting et al., 1999). Variedades ou genótipos altamente produtivos, por exemplo, podem ser menos sensíveis a mudanças nos fatores do solo, dada a sua maior eficiência no uso da água e de nutrientes (Vance, 2000). Outro fator relevante, no caso de florestas comerciais, é que as medidas de produtividade tradicionais (diâmetro, volume, peso) capturam apenas uma fração da atual produtividade do sítio, ou seja, a madeira, enquanto a produtividade associada com a produção de raízes, folhagem, estruturas de reprodução e serapilheira é geralmente ignorada, podendo-se, assim, ter uma indicação incompleta ou falsa do impacto do manejo sobre a produtividade em longo prazo.

A avaliação direta das propriedades do solo parece ser a forma mais adequada de medir ou monitorar a sua conservação ou qualquer processo de degradação em curso (Burger, 1996). Nesse contexto, a avaliação da qualidade do solo tem sido crescentemente proposta como um indicador integrado da qualidade do ambiente e da sustentabilidade da produção agrícola ou florestal. Qualidade do solo tem sido definida como "a capacidade de um tipo específico de solo funcionar, dentro dos limites do ecossistema manejado ou natural, como sustento para o desenvolvimento de plantas e de animais, de manter ou de aumentar a qualidade da água e do ar e de promover a saúde humana" (Doran \& Parkin, 1994). Para avaliar a qualidade do solo, indicadores químicos, físicos e biológicos devem ser identificados e analisados quanto à sua sensibilidade a mudanças e distúrbios causados pelo manejo. Uma vez que tenham sido definidos, esses indicadores podem ser monitorados de forma a avaliar o impacto do manejo adotado sobre a qualidade do solo em médio e longo prazo.

A análise de indicadores bioquímicos e microbiológicos de qualidade do solo é relevante quando se deseja obter informações sobre o desempenho de funções-chave do solo, como a capacidade de ciclar e armazenar nutrientes. Entretanto, existem poucas informações acerca do impacto de práticas de manejo florestais sobre indicadores microbiológicos em solos sob cultivo de eucalipto, especialmente em regiões tropicais, uma vez que as análises de rotina comumente adotadas para se avaliar o potencial produtivo de solos em florestas plantadas consideram apenas um número limitado de indicadores físicos e químicos. Embora os resultados dessas análises possam ser adotados para se definir em curto prazo as demandas por nutrientes e algumas limitações de ordem física, eles são insuficientes para avaliar em longo prazo o efeito das práticas de manejo em uso, ou sob avaliação em experimentos controlados, sobre a qualidade global dos solos, reconhecida no sentido mais amplo de equilíbrio de funções.

Além de constituírem informação complementar na avaliação qualitativa dos solos, os indicadores microbiológicos têm sido freqüentemente sugeridos como mais sensíveis aos impactos causados pelo manejo do solo, quando comparados àqueles de caráter físico ou químico (Staben et al., 1997; Trasar-Cepeda et al., 1998; Knoepp et al., 2000; Leirós et al., 2000; Bending et al., 2004). Essa característica pode ser de grande importância na distinção de tratamentos em experimentos em que se avaliam diferentes práticas de manejo, ou na avaliação precoce de eventuais efeitos adversos do manejo sobre a qualidade do solo, o que permitiria a adoção antecipada de medidas corretivas ou de controle.

O presente trabalho teve por objetivo avaliar variações de características físicas, químicas e microbiológicas, freqüentemente adotadas como indicadoras de qualidade do solo, em uma área experimental com eucalipto submetido a diferentes manejos quando da reforma do povoamento. Tendo em vista que a avaliação foi feita cinco anos e meio após a aplicação dos tratamentos, o trabalho objetivou também avaliar a sensibilidade dos indicadores em resposta aos impactos decorrentes dos sistemas de manejo testados.

\section{MATERIAL E MÉTODOS}

\section{Caracterização da área estudada}

O trabalho foi realizado com amostras de solos coletadas em área experimental instalada em março de 1995 pela Cia. Suzano de Papel e Celulose S/A, para estudar o efeito de diferentes manejos florestais sobre o crescimento do eucalipto (Eucalyptus grandis), e, também, com amostras de solos de uma área com vegetação nativa de mata secundária adjacente ao povoamento. A área experimental localiza-se no município de Botucatu-SP, fazenda Entre Rios, na latitude de $23^{\circ} 00$ ' S e longitude de $48^{\circ} 52^{\prime}$ 'W. O experimento foi montado em uma área de encosta com 
altitude média de $740 \mathrm{~m}$ e precipitação média de $1.200 \mathrm{~mm}$ anuais. O clima, segundo a classificação de Köppen, é do tipo Cwa, com chuvas típicas de clima tropical, caindo principalmente na primavera e no verão, com período seco no inverno e temperatura média anual entre 17 e $22{ }^{\circ} \mathrm{C}$ (Vianello \& Alves, 1991; Osaki, 1994). O solo da região é classificado como Neossolo Quartzarênico, e a produtividade média do eucalipto na rotação anterior foi de $31,5 \mathrm{~m}^{3} \mathrm{ha}^{-1} \mathrm{ano}^{-1}$. $\mathrm{O}$ experimento constituiu-se de um ensaio com seis tratamentos, dispostos em quatro blocos ao acaso. Em um dos tratamentos (área E11), as árvores oriundas do ciclo anterior, correspondente a um período de 5,5 anos de crescimento, foram mantidas. Em cada parcela de $654 \mathrm{~m}^{2}$, foi feito o plantio de $E$. grandis no espaçamento de $3 \times 1,8 \mathrm{~m}$, totalizando 49 plantas úteis por parcela. Foram realizadas adubações no sulco de plantio, exceto no tratamento em que não foi realizado o corte das árvores do primeiro ciclo (área E11), com $150 \mathrm{~kg} \mathrm{ha}^{-1}$ de fertilizante NPK na formulação 10-20-10 e $4 \mathrm{t} \mathrm{ha}^{-1}$ de cinza e, em cobertura, mais $150 \mathrm{~kg} \mathrm{ha}^{-1}$ do formulado. Em julho de 1997 foi realizada uma adubação de manutenção com $240 \mathrm{~kg} \mathrm{ha}^{-1}$ de fertilizante na formulação $16-00-32+$ $0,5 \%$ de $\mathrm{B}+1,5 \%$ de Zn, inclusive na área E11. Às áreas foram atribuídos os seguintes códigos de identificação: AVN - área de vegetação natural de mata secundária; E11 - área onde não foi realizado o corte das árvores do primeiro ciclo (eucalipto com 11 anos); RCM - reforma sem a remoção de resíduos (cultivo mínimo); RGC - reforma com remoção dos restos culturais (galhos e cascas); RCS - reforma com remoção dos restos culturais e da serapilheira; INC - reforma com incorporação de todos os resíduos com grade; $\mathrm{e}$ $\mathrm{RCQ}$ - reforma com a queima de todos os resíduos.

\section{Amostragem do solo}

A coleta das amostras de solo foi realizada em agosto de 2000, quando o plantio do eucalipto se encontrava com 5,5 anos de idade, à exceção daquele na área E11, com idade de 11 anos, onde o povoamento fora mantido por ocasião da reforma nas demais áreas. A amostragem foi aleatória, retirando-se 12 amostras simples das camadas de 0 a $5 \mathrm{~cm}$ e de 5 a $20 \mathrm{~cm}$ em cada parcela experimental. As amostras simples foram peneiradas em campo em peneira com malha de 2 mm de diâmetro e misturadas, para constituírem uma única amostra composta por parcela, totalizando quatro repetições por tratamento. Retirou-se também de cada parcela uma amostra não-deformada da profundidade de 0 a $5 \mathrm{~cm}$, para determinação da densidade do solo.

Foram coletadas também amostras de solo de uma área vizinha ao ensaio (cerca de $500 \mathrm{~m}$ de distância) com vegetação natural de mata secundária, constituindo-se em material de referência. $\mathrm{O}$ procedimento de amostragem nesta área foi semelhante ao descrito para a área experimental. No entanto, a área foi dividida em quatro partes, de modo a se ter quatro repetições. O critério utilizado para divisão da área de vegetação natural foi a posição em relação à encosta, o qual foi o mesmo daquele utilizado para definir os blocos do experimento florestal situado na mesma encosta. Dessa forma, foram totalizados sete conjuntos de amostras, constituindo sete tratamentos, sendo seis deles referentes aos solos sob eucalipto submetido aos diferentes manejos e um referente ao solo de vegetação natural.

\section{Métodos analíticos}

De cada amostra composta foram retiradas porções de aproximadamente $500 \mathrm{~g}$, para avaliação das características químicas e físicas. Dada a textura arenosa do solo em todas as amostras e a estrutura em grãos simples, dentre as análises físicas foram determinadas somente a densidade do solo, utilizandose de cilindros de $6 \mathrm{~cm}$ de diâmetro para coleta de amostras com estrutura indeformada, e a granulometria, utilizando-se o método do densímetro (Embrapa, 1997). Dentre as características químicas, foram feitas as seguintes avaliações, utilizando-se protocolos descritos em Embrapa (1999): teor de matéria orgânica; $\mathrm{pH} \mathrm{em} \mathrm{CaCl}_{2}$; teores de $\mathrm{P}, \mathrm{K}^{+}, \mathrm{Ca}^{2+}$ e $\mathrm{Mg}^{2+}$ (resina trocadora de íons); acidez trocável $\left(\mathrm{Al}^{3+}\right)$ e acidez potencial $(\mathrm{H}+\mathrm{Al})$; soma de bases (SB); CTC pH 7 (T); e saturação por bases (V) e saturação por $\mathrm{Al}^{3+}(\mathrm{m})$.

O conteúdo de fósforo orgânico do solo foi determinado pelo método de ignição do solo em mufla (Anderson \& Ingram, 1996). O P-orgânico foi calculado pela diferença do conteúdo de $\mathrm{P}$ nos extratos ácidos das amostras tratadas e não-tratadas com ignição (Braga \& Defelipo, 1974).

As análises microbiológicas foram feitas a partir de subamostras mantidas sob refrigeração (aproximadamente $4{ }^{\circ} \mathrm{C}$ ) desde o transporte do campo até o momento da análise. As atividades das enzimas, $\beta$-glicosidase (Eivazi \& Tabatabai, 1988), fosfomonoesterases ácida e alcalina (Tabatabai, 1994), urease (Kempers \& Zweers, 1986) e das desidrogenases (Lenhard, 1956, citado por Tabatabai, 1994) foram determinadas segundo métodos publicados.

O carbono da biomassa microbiana (CBM) foi determinado pelo método proposto por Vance et al. (1987), modificado por Islam \& Weil (1998), exceto pela fumigação das amostras de solo, que foi realizada com clorofórmio. Para cálculo do teor de CBM, utilizouse um valor de Kc igual a 0,38 (Vance et al., 1987). A partir dos valores do CBM e do conteúdo de matéria orgânica, foi determinado o quociente microbiano ( $q \mathrm{MIC}$ ), que representa a percentagem do carbono orgânico do solo que é representado pelo CBM. A transformação dos valores de carbono orgânico para matéria orgânica foi feita pela relação $\mathrm{MO}=$ 1,724 x CO (Alvarez V. et al., 1999).

A extração do nitrogênio da biomassa microbiana (NBM) foi feita semelhantemente à extração do CBM. Obtido o extrato do solo de amostras fumigadas com 
clorofórmio e não-fumigadas, determinou-se o nitrogênio reativo a ninhidrina da biomassa microbiana (Joergensen \& Brookes, 1990). O NBM total foi estimado multiplicando-se por 5 os valores encontrados para o $\mathrm{N}$ reativo a ninhidrina, conforme proposto por Joergensen \& Brookes (1990).

A atividade respiratória da biomassa microbiana, ou respiração basal do solo, foi avaliada pela quantificação do $\mathrm{CO}_{2}$ liberado durante a incubação do solo em sistema fechado, onde o $\mathrm{CO}_{2}$ foi capturado em solução de $\mathrm{NaOH} 0,05 \mathrm{~mol} \mathrm{~L}^{-1}$ e posteriormente titulado com $\mathrm{HCl}$ (Isermeyer, 1952). Foi calculado o quociente metabólico $\left(q \mathrm{CO}_{2}\right)$, que representa a respiração microbiana por unidade de biomassa por unidade de tempo (Anderson \& Domsch, 1985).

A determinação das taxas de nitrificação e de amonificação líquidas foi feita segundo método descrito por Hart et al. (1994). O teor de $\mathrm{N}_{-} \mathrm{NH}_{4}{ }^{+}$nas amostras incubadas e não-incubadas foi medido pelo método colorimétrico (Kempers \& Zweers, 1986). O teor de $\mathrm{N}-\mathrm{NO}_{3}{ }^{-}$nas mesmas amostras foi avaliado por método de determinação espectrofotométrica do nitrato em água (Mullin \& Riley, 1955), com modificações propostas por Cantarutti \& Pinheiro (np), como descrito a seguir. Após extração, foram colocados em tubos de ensaio $2 \mathrm{~mL}$ da amostra e os demais reagentes, na seguinte ordem: $1 \mathrm{~mL}$ de hidróxido de sódio $0,3 \mathrm{~mol} \mathrm{~L}^{-1}$; $0,5 \mathrm{~mL}$ de sulfato de cobre a $0,14 \mathrm{mmol} \mathrm{L}^{-1} ; 1 \mathrm{~mL}$ de sulfato de hidrazina a $2,3 \mathrm{mmol} \mathrm{L}^{-1}$; e $3,5 \mathrm{~mL}$ de cloreto de potássio a $1 \mathrm{~mol} \mathrm{~L}^{-1}$. Os tubos foram deixados em banho-maria a $80^{\circ} \mathrm{C}$ por 15 min e em seguida permaneceram em temperatura ambiente por $30 \mathrm{~min}$, para resfriamento. Adicionou-se, a seguir, $1 \mathrm{~mL}$ de solução de sulfanilamida a 2,9 $\mathrm{mmol} \mathrm{L}^{-1}$; os tubos foram agitados e, após cinco minutos, adicionou-se $1 \mathrm{~mL}$ de solução de N-1-naftil etilenodiamino bicloridrato a $1,2 \mathrm{mmol} \mathrm{L}^{-1}$. Após 20 min, foi medida a absorvância da mistura em espectrofotômetro, com comprimento de onda ajustado para $540 \mathrm{~nm}$. O cálculo da concentração de nitrato foi feito usando uma curva-padrão com a concentração variando de $0,02 \mathrm{a}_{2} \mathrm{mg} \mathrm{L}^{-1}$ de N-NO ${ }_{3}^{-}$.

A taxa de nitrificação líquida foi calculada segundo Hart et al. (1994), pela diferença entre o teor de N$\mathrm{NO}_{3}{ }^{-}$no solo seco no tempo $t_{0}$ (início da incubação) e $\mathrm{t}+1$ (intervalo de tempo de incubação das amostras, 28 dias). A taxa de amonificação líquida foi determinada pela fórmula: Alíq (mmol g-1 $\mathrm{d}^{-1} \mathrm{de} \mathrm{N}$ no

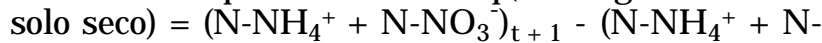
$\left.\mathrm{NO}_{3}{ }^{-}\right)_{\text {t0 }}$ (Hart et al., 1994).

\section{Análises estatísticas}

Todas as análises estatísticas foram realizadas com o auxílio dos softwares Saeg ${ }^{\circledR}$ (Euclydes, 2003) e Statistica ${ }^{\circledR}$ (StatSoft, 1995). Foram realizadas as análises de variância e aplicado o teste de médias de Tukey a $5 \%$ para as variáveis que apresentaram efeito de tratamento significativo. As fontes de variação consideradas na análise de variância foram manejo florestal e bloco.
Para revelar similaridades e diferenças entre as áreas avaliadas e o relacionamento entre as características do solo analisadas, foi aplicada a análise de componentes principais, considerando-se os valores médios de todas as variáveis físicas, químicas e biológicas determinadas. Anteriormente à análise multivariada dos dados, estes foram padronizados (média/desvio-padrão), para assegurar que todas as variáveis contribuíssem igualmente para o modelo, independentemente da escala pela qual elas foram medidas.

\section{RESULTADOS E DISCUSSÃO}

\section{Caracterização física e química do solo}

A análise de características físicas e químicas não apontou diferenças significativas entre os solos sob vegetação nativa e aqueles sob monoculturas de eucalipto submetidos aos diferentes manejos florestais (Quadro 1), exceto para os teores de P-orgânico e $\mathrm{K}^{+}$, cujos valores foram maiores nos solos sob vegetação nativa.

Reconhece-se que a queima de restos culturais, ou o cultivo com intensa exposição do solo à mineralização, proporciona perdas de fósforo orgânico, bem como o predomínio de formas mais recalcitrantes (menos lábeis). Essas alterações resultam em menor participação do P-orgânico como fonte de $\mathrm{P}$ para as plantas, de modo que o suprimento desse nutriente às plantas fica restrito à fase mineral. Paulatinamente, 0 sistema anteriormente otimizado pelo suprimento de $\mathrm{P}$ presente como P-orgânico, característico das áreas com vegetação nativa, torna-se cada vez mais dependente do suprimento de fertilizantes (Novais et al., 1999). A forma e a dinâmica do $\mathrm{P}$ no solo podem ser afetadas significativamente por mudanças no uso da terra, incluindo mudanças na cobertura vegetal, na produção de biomassa e na ciclagem de nutrientes (Magid et al., 1996). Bettany et al. (1979) sugeriram que, em serapilheira de florestas, altas taxas de decomposição resultam na produção de ácidos orgânicos de baixo peso molecular, os quais podem ser translocados para baixo da camada explorada pelas raízes. Esse processo acarretaria a remoção do $\mathrm{P}$ do processo de ciclagem ativa. Em ecossistemas natural (sem uso agrícola), a ciclagem do $\mathrm{P}$ dentro e entre as formas orgânicas e inorgânicas no solo é predominantemente fechada, com poucas perdas ocasionadas pela lixiviação ou colheita e remoção de biomassa. Em sistemas fechados, a ciclagem e as formas do $\mathrm{P}$ são determinadas por fatores como topografia, clima, material de origem do solo, biomassa e tempo (Solomon et al., 2002). Contudo, quando os solos são convertidos à agricultura, as entradas e saídas de $\mathrm{P}$ são alteradas, o que resulta em alteração do balanço de $\mathrm{P}$ e mudança nas formas do elemento. Essas mudanças refletem as que ocorrem na matéria orgânica do solo e na biomassa pela remoção 
Quadro 1. Caracterização físico-química das amostras de solo sob plantio de eucalipto retiradas de parcelas submetidas a diferentes manejos culturais e de uma área com vegetação natural adjacente, localizadas na fazenda Entre Rios, Botucatu-SP

\begin{tabular}{|c|c|c|c|c|c|c|c|c|c|c|c|c|c|c|c|c|c|c|c|}
\hline Área ${ }^{(1)}$ & Prof. & $\begin{array}{c}\mathrm{pH} \\
\mathrm{CaCl}_{2}\end{array}$ & мо & P-org. & P-resina & $\mathrm{S}_{-} \mathrm{SO}_{4}{ }^{2-}$ & $\mathbf{K}^{+}$ & $\mathrm{Ca}^{2+}$ & $\mathrm{Mg}^{2+}$ & $\mathrm{Al}^{3+}$ & $\mathrm{H}+\mathrm{Al}$ & SB & $\mathbf{T}$ & $\mathrm{v}$ & $\mathbf{m}$ & Areia & Silte & Argila & Densidade \\
\hline & $\mathrm{cm}$ & & dag $\mathrm{kg}^{-1}$ & & $-\mathrm{mg} \mathrm{dm}^{-3}$ & & & & $-\mathrm{cm}$ & ${ }_{10 l_{c}} \mathrm{dm}^{-3}$ & & & & & & $-\%-$ & & - & $\mathrm{kg} \mathrm{dm}^{-3}$ \\
\hline \multirow[t]{2}{*}{ AVN } & $0-5$ & $3,47 \mathrm{a}$ & $3,20 \mathrm{a}$ & $2,69 \mathrm{a}$ & $7,5 \mathrm{a}$ & $17,0 \mathrm{a}$ & $0,105 \mathrm{a}$ & $0,600 a$ & $0,300 \mathrm{a}$ & $1,20 \mathrm{a}$ & $7,10 \mathrm{a}$ & $1,005 \mathrm{a}$ & $8,11 \mathrm{a}$ & $12,75 \mathrm{a}$ & $56,00 \mathrm{a}$ & $92,0 \mathrm{a}$ & $2,0 \mathrm{a}$ & $6,0 \mathrm{a}$ & $1,07 \mathrm{a}$ \\
\hline & $5-20$ & $3,42 B$ & $2,23 \mathrm{~A}$ & $2,14 \mathrm{~A}$ & $6,25 \mathrm{~A}$ & $16,25 \mathrm{~A}$ & $0,070 \mathrm{~A}$ & $0,250 \mathrm{~A}$ & $0,150 \mathrm{~A}$ & $1,28 \mathrm{~A}$ & $6,35 \mathrm{~A}$ & $0,470 \mathrm{~A}$ & $6,82 \mathrm{~A}$ & $6,75 \mathrm{~A}$ & $73,25 \mathrm{~A}$ & $91,5 \mathrm{~A}$ & $2,0 \mathrm{~A}$ & $6,5 \mathrm{~A}$ & - \\
\hline \multirow[t]{2}{*}{ E11 } & $0-5$ & $3,53 \mathrm{a}$ & $2,60 \mathrm{a}$ & $1,20 \mathrm{~b}$ & $7,3 \mathrm{a}$ & $14,8 \mathrm{a}$ & $0,063 \mathrm{~b}$ & $0,450 \mathrm{a}$ & $0,225 \mathrm{a}$ & $1,03 \mathrm{a}$ & $5,53 \mathrm{a}$ & $0,788 \mathrm{a}$ & $6,31 \mathrm{a}$ & $12,75 \mathrm{a}$ & $56,75 \mathrm{a}$ & $92,0 \mathrm{a}$ & $2,5 \mathrm{a}$ & $5,5 \mathrm{a}$ & $1,09 \mathrm{a}$ \\
\hline & $5-20$ & $3,70 \mathrm{~A}$ & $2,00 \mathrm{~A}$ & $1,30 \mathrm{~B}$ & $5,25 \mathrm{~A}$ & $15,5 \mathrm{~A}$ & $0,052 \mathrm{AB}$ & $0,275 \mathrm{~A}$ & $0,175 \mathrm{~A}$ & $1,00 \mathrm{~A}$ & $4,38 \mathrm{~A}$ & $0,503 \mathrm{~A}$ & $4,88 \mathrm{~A}$ & $10,75 \mathrm{~A}$ & $66,75 \mathrm{~A}$ & $92,0 \mathrm{~A}$ & $2,5 \mathrm{~A}$ & $4,5 \mathrm{~A}$ & - \\
\hline \multirow[t]{2}{*}{$\mathrm{RCM}$} & $0-5$ & $3,85 \mathrm{a}$ & $2,72 \mathrm{a}$ & $1,59 \mathrm{~b}$ & $10,3 \mathrm{a}$ & $15,5 \mathrm{a}$ & $0,070 \mathrm{ab}$ & $1,280 \mathrm{a}$ & $0,350 \mathrm{a}$ & $0,80 \mathrm{a}$ & $5,48 \mathrm{a}$ & $1,695 \mathrm{a}$ & $7,17 \mathrm{a}$ & $24,50 \mathrm{a}$ & $37,25 \mathrm{a}$ & $91,5 \mathrm{a}$ & $3,0 \mathrm{a}$ & $5,5 \mathrm{a}$ & $1,19 \mathrm{a}$ \\
\hline & $5-20$ & $3,72 \mathrm{~A}$ & $2,03 \mathrm{~A}$ & $1,50 \mathrm{~B}$ & $8,50 \mathrm{~A}$ & $13,75 \mathrm{~A}$ & $0,057 \mathrm{AB}$ & $0,350 \mathrm{~A}$ & $0,175 \mathrm{~A}$ & $0,90 \mathrm{~A}$ & $4,40 \mathrm{~A}$ & $0,582 \mathrm{~A}$ & $4,98 \mathrm{~A}$ & $12,25 \mathrm{~A}$ & $61,00 \mathrm{~A}$ & $91,0 \mathrm{~A}$ & $2,5 \mathrm{~A}$ & $6,5 \mathrm{~A}$ & - \\
\hline \multirow[t]{2}{*}{$\mathrm{RGC}$} & $0-5$ & $3,80 \mathrm{a}$ & $2,83 \mathrm{a}$ & $1,57 \mathrm{~b}$ & $10,3 \mathrm{a}$ & $13,0 \mathrm{a}$ & $0,063 \mathrm{~b}$ & $1,230 \mathrm{a}$ & $0,325 \mathrm{a}$ & $0,80 \mathrm{a}$ & $5,20 \mathrm{a}$ & $1,613 \mathrm{a}$ & $6,81 \mathrm{a}$ & $24,00 \mathrm{a}$ & $37,75 \mathrm{a}$ & $91,0 \mathrm{a}$ & $3,5 \mathrm{a}$ & $5,5 \mathrm{a}$ & $1,21 \mathrm{a}$ \\
\hline & $5-20$ & $3,75 \mathrm{~A}$ & $1,83 \mathrm{~A}$ & $1,46 \mathrm{~B}$ & $7,75 \mathrm{~A}$ & $13,0 \mathrm{~A}$ & $0,047 \mathrm{~B}$ & $0,275 \mathrm{~A}$ & $0,175 \mathrm{~A}$ & $0,98 \mathrm{~A}$ & $4,65 \mathrm{~A}$ & $0,497 \mathrm{~A}$ & $5,15 \mathrm{~A}$ & $10,25 \mathrm{~A}$ & $66,50 \mathrm{~A}$ & $90,5 \mathrm{~A}$ & $3,0 \mathrm{~A}$ & $6,5 \mathrm{~A}$ & - \\
\hline \multirow[t]{2}{*}{ RCS } & $0-5$ & $3,88 \mathrm{a}$ & $2,48 \mathrm{a}$ & $2,02 \mathrm{ab}$ & $8,0 \mathrm{a}$ & $12,0 \mathrm{a}$ & $0,063 \mathrm{~b}$ & $0,950 \mathrm{a}$ & $0,325 \mathrm{a}$ & $0,78 \mathrm{a}$ & $4,53 \mathrm{a}$ & $1,338 \mathrm{a}$ & $5,86 \mathrm{a}$ & $23,25 \mathrm{a}$ & $38,50 \mathrm{a}$ & $92,0 \mathrm{a}$ & $2,5 \mathrm{a}$ & $5,5 \mathrm{a}$ & $1,26 \mathrm{a}$ \\
\hline & $5-20$ & $3,78 \mathrm{~A}$ & $1,83 \mathrm{~A}$ & $1,10 \mathrm{~B}$ & $5,50 \mathrm{~A}$ & $13,0 \mathrm{~A}$ & $0,050 \mathrm{~B}$ & $0,375 \mathrm{~A}$ & $0,200 \mathrm{~A}$ & $0,80 \mathrm{~A}$ & $4,08 \mathrm{~A}$ & $0,625 \mathrm{~A}$ & $4,70 \mathrm{~A}$ & $14,00 \mathrm{~A}$ & $56,25 \mathrm{~A}$ & $90,5 \mathrm{~A}$ & $4,0 \mathrm{~A}$ & $5,5 \mathrm{~A}$ & - \\
\hline \multirow[t]{2}{*}{ INC } & $0-5$ & $3,75 \mathrm{a}$ & $2,50 \mathrm{a}$ & $1,57 \mathrm{~b}$ & $9,5 \mathrm{a}$ & $13,3 \mathrm{a}$ & $0,065 \mathrm{~b}$ & $0,830 \mathrm{a}$ & $0,350 \mathrm{a}$ & $0,73 \mathrm{a}$ & $4,38 \mathrm{a}$ & $1,240 \mathrm{a}$ & $5,62 \mathrm{a}$ & $22,00 \mathrm{a}$ & $37,25 \mathrm{a}$ & $91,5 \mathrm{a}$ & $2,5 \mathrm{a}$ & $6,0 \mathrm{a}$ & $1,16 \mathrm{a}$ \\
\hline & $5-20$ & $3,70 \mathrm{~A}$ & $1,95 \mathrm{~A}$ & $1,35 \mathrm{~B}$ & $7,75 \mathrm{~A}$ & $13,50 \mathrm{~A}$ & $0,047 \mathrm{~B}$ & $0,375 \mathrm{~A}$ & $0,225 \mathrm{~A}$ & $0,88 \mathrm{~A}$ & $4,68 \mathrm{~A}$ & $0,647 \mathrm{~A}$ & $5,32 \mathrm{~A}$ & $12,75 \mathrm{~A}$ & $77,75 \mathrm{~A}$ & $90,5 \mathrm{~A}$ & $3,5 \mathrm{~A}$ & $6,0 \mathrm{~A}$ & - \\
\hline \multirow[t]{2}{*}{$\mathrm{RCQ}$} & $0-5$ & $3,83 \mathrm{a}$ & $3,03 \mathrm{a}$ & $1,50 \mathrm{~b}$ & $11,0 \mathrm{a}$ & $13,0 \mathrm{a}$ & $0,073 \mathrm{ab}$ & $0,930 \mathrm{a}$ & $0,375 \mathrm{a}$ & $0,75 \mathrm{a}$ & $5,25 \mathrm{a}$ & $1,373 \mathrm{a}$ & $6,62 \mathrm{a}$ & $22,25 \mathrm{a}$ & $34,25 \mathrm{a}$ & $91,5 \mathrm{a}$ & $2,0 \mathrm{a}$ & $6,5 \mathrm{a}$ & $1,14 \mathrm{a}$ \\
\hline & $5-20$ & $3,75 \mathrm{~A}$ & $1,83 \mathrm{~A}$ & $1,24 \mathrm{~B}$ & $6,00 \mathrm{~A}$ & $13,0 \mathrm{~A}$ & $0,043 \mathrm{~B}$ & $0,275 \mathrm{~A}$ & $0,175 \mathrm{~A}$ & $0,85 \mathrm{~A}$ & $4,20 \mathrm{~A}$ & $0,493 \mathrm{~A}$ & $4,69 \mathrm{~A}$ & $10,75 \mathrm{~A}$ & $65,25 \mathrm{~A}$ & $91,5 \mathrm{~A}$ & $2,0 \mathrm{~A}$ & $6,5 \mathrm{~A}$ & - \\
\hline
\end{tabular}

SB: soma de bases; T: CTC pH 7; V: saturação por bases; m: saturação por alumínio.

Médias seguidas pela mesma letra minúscula $(0$ a $5 \mathrm{~cm})$ ou maiúscula $(5$ a $20 \mathrm{~cm})$, na coluna, não diferem entre si pelo teste de Tukey a $5 \%$.

(1) AVN: área de vegetação natural de mata secundária, E11: área onde não foi realizado o corte das árvores do primeiro ciclo (eucalipto com 11 anos), RCM: reforma sem a remoção de resíduos (cultivo mínimo), RGC: reforma com remoção dos restos culturais (galhos e cascas), RCS: reforma com remoção dos restos culturais e da serapilheira, INC: reforma com incorporação de todos os resíduos com grade e RCQ: reforma com a queima de todos os resíduos.

com as colheitas e entradas por meio da fertilização (Magid et al., 1996). Por exemplo, Bowman et al. (1990) relataram que, três anos após a conversão de um solo sob vegetação nativa para uso agrícola, o $\mathrm{P}$ orgânico total decresceu cerca de $60 \%$.

Não foram observadas diferenças significativas no teor de matéria orgânica entre as áreas estudadas. Segundo Waring \& Schlesinger (1985), o corte de uma floresta usualmente causa pouca mudança na matéria orgânica ou no conteúdo de nutrientes no solo mineral, mas a serapilheira pode declinar por vários anos depois do corte, em razão de a taxa de aporte do folhedo da vegetação regenerativa não ser igual à taxa de queda do folhedo que ocorre na área antes do corte das árvores. Durante esse período, é esperada grande perda de nutrientes, devido à decomposição do material orgânico depositado nesses locais. Gama-Rodrigues (1997), trabalhando no sul da Bahia, não encontrou diferença significativa nos teores de C orgânico e N total de solos sob diferentes coberturas florestais. Em estudos com povoamentos de eucalipto em solos arenosos no município de Aracruz-ES, também têm sido observados teores de CO semelhantes aos encontrados em solos com mata nativa primária (dados não apresentados).

$\mathrm{O}$ pH $\left(\mathrm{CaCl}_{2}\right)$ na camada de 5 a $20 \mathrm{~cm}$ do solo sob vegetação natural foi menor do que o das áreas com eucalipto, apesar de todos os solos analisados apresentarem acidez bastante elevada, com valores de $\mathrm{pH}$ em $\mathrm{CaCl}_{2}$ em torno de 3,7 em ambas as profundidades. Todas as amostras apresentaram granulometria semelhante, com teores de areia superiores a $90 \%$. A densidade na camada de 0 a $5 \mathrm{~cm}$ de profundidade variou de $1,07 \mathrm{~g} \mathrm{~cm}^{-3}$ no solo de vegetação natural a $1,26 \mathrm{~g} \mathrm{~cm}^{-3}$ no solo sob eucalipto submetido ao manejo com a retirada da serapilheira e dos restos culturais (área RCS), sem apresentar, no entanto, diferença significativa entre as áreas.

Os solos sob vegetação nativa e os das áreas sob monocultura de eucalipto submetidas aos diferentes métodos de preparo mostraram-se homogêneos quando comparados por meio da maioria dos indicadores químicos e físicos avaliados. É relevante o fato de que os indicadores físicos e, principalmente, os químicos são os comumente adotados para mensuração da qualidade dos solos nas análises de rotina. A análise dos dados obtidos neste estudo demonstra que o uso desses indicadores não foi capaz de discriminar efeito de uso ou manejo do solo.

\section{Características bioquímicas e microbiológicas}

Os maiores valores do carbono da biomassa microbiana (CBM) e do nitrogênio da biomassa microbiana (NBM) foram encontrados no solo sob vegetação natural (Quadro 2). O valor de CBM na camada de 0 a $5 \mathrm{~cm}$, nessa área, foi significativamente maior $(p<0,05)$ do que o encontrado nas áreas cujo 
manejo conduziu à perda do material orgânico da superfície: RCS (reforma com remoção dos restos culturais e da serapilheira), INC (reforma com incorporação de todos os resíduos com grade) e RCQ (reforma com a queima de todos os resíduos). $\mathrm{Na}$ profundidade de 5 a $20 \mathrm{~cm}$, apenas as áreas E11 (em que não foi realizado o corte das árvores do primeiro ciclo) e INC apresentaram valores que não diferiram do obtido na área com vegetação natural. Não houve efeito de tratamentos nas áreas de eucalipto sobre o CBM, em ambas as profundidades, indicando que eventuais efeitos ocorridos por ocasião da reforma dos povoamentos de eucalipto não prevaleceram ao longo do crescimento da floresta.

O NBM foi mais sensível quanto à mudança do uso do solo do que o CBM. Em ambas as camadas estudadas, os valores encontrados na área com vegetação nativa foram significativamente maiores do que os obtidos em todas as áreas com povoamentos de eucalipto (Quadro 2). A única exceção foi a área INC na camada de 5-20 cm, cujo valor de NBM não diferiu do encontrado na AVN. Esse resultado é coerente com os dados de CBM nessa mesma camada de solo, sendo atribuído à incorporação dos resíduos orgânicos pelo manejo empregado na reforma dessa área.

O CBM e o NBM apresentaram variações significativas entre as áreas estudadas. Os valores absolutos dessas variáveis foram consistentemente mais elevados no solo sob vegetação natural, indicando a ocorrência de efeitos adversos da monocultura de eucalipto sobre a biomassa microbiana do solo. Por outro lado, não foram detectadas alterações significativas no teor de matéria orgânica total (Quadro 1), o que demonstra, conforme também observado por outros autores (Powlson et al., 1987; Anderson \& Domsch, 1989; Sparling, 1992), que a biomassa microbiana é mais sensível que a matéria orgânica total às alterações decorrentes do uso do solo. Foi encontrada alta correlação positiva entre o CBM e o NBM, tanto na camada de $0-5 \mathrm{~cm}(\mathrm{r}=0,93$; $p<0,001)$ quanto na de $5-20 \mathrm{~cm}(\mathrm{r}=0,95 ; p<0,001)$, o que implica uma relação $\mathrm{C}: \mathrm{N}$ relativamente invariável na biomassa microbiana nas áreas estudadas (C:N = 4,37 $\pm 0,57$ a 0-5 cm e C:N = 5,96 \pm 0,69 a $5-20 \mathrm{~cm}$ ) (dados não apresentados). Elevadas correlações entre o CBM e o NBM são também reportadas por Joergensen \& Brookes (1990) e por Mondini et al. (2002).

Neste estudo, os valores da relação entre o C microbiano e o C orgânico ( $q \mathrm{MIC}$ ) variaram entre 0,81 e 1,54\% (Quadro 2), abaixo dos encontrados em alguns solos sob culturas agrícolas (2-7 \%) (Sorensen, 1987; Anderson \& Domsch, 1989; Kandeler et al., 1993). Em solos arenosos sob eucalipto no Espírito Santo, consistentemente têm-se encontrado valores de $q \mathrm{MIC}$ variando entre 0,2 e $0,8 \%$, em amostragens de solo realizadas no final da estação chuvosa (dados não publicados). Essa menor proporção entre $\mathrm{C}$ microbiano e CO nos solos mencionados, comparativamente aos valores reportados para solos localizados em regiões de clima temperado, pode estar relacionada à menor disponibilidade de nutrientes minerais para sustentar a biomassa microbiana, à inibição dos microrganismos do solo por acidez excessiva ou toxicidade de $\mathrm{Al}^{3+}$ ou a ambos. Além disso, segundo Insam et al. (1991), condições mais estáveis de temperatura e precipitação propiciam menor relação entre o $\mathrm{C}$ microbiano e o $\mathrm{C}$ orgânico, ao passo que condições mais flutuantes ou extremas favorecem um maior $q$ MIC. É possível que essa seja também uma explicação plausível para valores mais baixos de $q$ MIC encontrados neste trabalho, comparativamente aos reportados em solos localizados em regiões de clima temperado, caracterizadas por apresentarem extremos de temperatura. Igualmente, essa pode ser a razão para os menores valores de $q \mathrm{MIC}$ encontrados em solos sob eucalipto na região litorânea do Espírito Santo, comparativamente aos reportados neste estudo. Essa opinião, contudo, precisa ser comprovada por estudos específicos.

Os maiores valores absolutos de $q$ MIC foram encontrados no solo sob vegetação natural (Quadro 2). Entretanto, diferença significativa foi encontrada somente entre as áreas de vegetação natural (AVN) e a área submetida à queima dos resíduos orgânicos (RCQ), na camada de 0-5 cm, e entre a área AVN e a área de cultivo mínimo (RCM), na camada de 5-20 cm. Anderson \& Domsch (1989) observaram maior valor de $q \mathrm{MIC}$ em área de cultivo sob rotação de culturas do que em áreas sob monocultura. A mudança quantitativa do CBM de solos submetidos a diferentes regimes de manejo foi atribuída à maior quantidade e diversidade de resíduos deixados nas áreas sob rotação. Esses autores hipotetizaram que, se a disponibilidade de $\mathrm{C}$ for uma das variáveis que direcionam a relação $\mathrm{C}$ microbiano: $\mathrm{C}$ orgânico, a maior diversidade química da matéria orgânica produzida nas áreas com rotação de culturas poderia favorecer os organismos que são dotados de um metabolismo mais econômico. Assim, menos $\mathrm{C}$ de um substrato orgânico seria canalizado para o metabolismo energético e mais $\mathrm{C}$ seria fixado nas células microbianas, afetando, desse modo, a relação C microbiano:C orgânico ( $>$ MIC). Efeito semelhante deve explicar os valores absolutos mais elevados de $q \mathrm{MIC}$ reportados na área sob vegetação nativa. Esse padrão também foi observado por Behera \& Sahani (2003), ao compararem solos de vegetação natural com os de plantios de eucalipto em solos tropicais. Segundo Wardle (1994), em circunstâncias em que a biomassa se encontra sob algum fator de estresse (deficiência de nutrientes, acidez, entre outros), a capacidade de utilização do carbono é reduzida. Nesse caso, a relação C microbiano:C orgânico diminui $(<q \mathrm{MIC})$. Ao contrário, maiores valores de $q \mathrm{MIC}$ indicam condições mais apropriadas para o desenvolvimento microbiano, as quais podem decorrer da adição de matéria orgânica de boa qualidade ou da eliminação do fator limitante. Nesse caso, a biomassa microbiana pode aumentar, 
Quadro 2. Carbono da biomassa microbiana (CBM), nitrogênio da biomassa microbiana (NBM), quociente microbiano ( $q \mathrm{MIC})$, atividade respiratória basal e quociente metabólico $\left(q \mathrm{CO}_{2}\right)$ em amostras de solo sob plantio de eucalipto, retiradas de parcelas submetidas a diferentes manejos culturais e de uma área com vegetação natural adjacente

\begin{tabular}{|c|c|c|c|c|c|c|c|c|c|c|}
\hline \multirow[b]{2}{*}{ Área ${ }^{(1)}$} & \multicolumn{2}{|c|}{ CBM } & \multicolumn{2}{|c|}{ NBM } & \multicolumn{2}{|c|}{$q \mathrm{MIC}$} & \multicolumn{2}{|c|}{ Respiração } & \multicolumn{2}{|c|}{$q \mathrm{CO}_{2}$} \\
\hline & $0-5 \mathrm{~cm}$ & $5-20 \mathrm{~cm}$ & $0-5 \mathrm{~cm}$ & $5-20 \mathrm{~cm}$ & $0-5 \mathrm{~cm}$ & $5-20 \mathrm{~cm}$ & $0-5 \mathrm{~cm}$ & $5-20 \mathrm{~cm}$ & $0-5 \mathrm{~cm}$ & $5-20 \mathrm{~cm}$ \\
\hline & \multicolumn{2}{|c|}{ - $\mathrm{mg} \mathrm{kg}^{-1}$ de $\mathrm{C}$ - } & \multicolumn{2}{|c|}{$-\mathrm{mg} \mathrm{kg}^{-1}$ de $\mathrm{N}-$} & 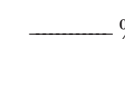 & $\%$ & \multicolumn{2}{|c|}{$-\mathrm{mg} \mathrm{kg}^{-1} \mathrm{~h}^{-1}$ de C- $\mathrm{CO}_{2}-$} & \multicolumn{2}{|c|}{$\begin{array}{c}\mathrm{mg} \mathrm{g}^{-1} \mathrm{~h}^{-1} \text { de } \mathrm{C}-\mathrm{CO}_{2} \\
\text { do C-biomassa }\end{array}$} \\
\hline AVN & $262,6 \mathrm{a}$ & $197,4 \mathrm{a}$ & $76,4 \mathrm{a}$ & $37,8 \mathrm{a}$ & $1,50 \mathrm{a}$ & $1,54 \mathrm{a}$ & $1,221 \mathrm{ab}$ & $0,696 \mathrm{a}$ & $4,6 \mathrm{~b}$ & $3,5 \mathrm{a}$ \\
\hline E11 & $181,3 \mathrm{ab}$ & $144,3 \mathrm{ab}$ & $36,3 \mathrm{~b}$ & $21,0 \mathrm{~b}$ & $1,20 \mathrm{ab}$ & $1,27 \mathrm{ab}$ & $1,262 \mathrm{a}$ & $0,608 \mathrm{ab}$ & $7,0 \mathrm{ab}$ & $4,2 \mathrm{a}$ \\
\hline $\mathrm{RCM}$ & $185,3 \mathrm{ab}$ & $115,6 \mathrm{~b}$ & $38,6 \mathrm{~b}$ & $20,5 b$ & $1,18 \mathrm{ab}$ & $0,98 b$ & $1,071 \mathrm{abc}$ & $0,404 b$ & $5,8 \mathrm{ab}$ & $3,5 \mathrm{a}$ \\
\hline $\mathrm{RGC}$ & $182,0 \mathrm{ab}$ & $121,2 \mathrm{~b}$ & $40,7 \mathrm{~b}$ & $17,4 \mathrm{~b}$ & $1,14 \mathrm{ab}$ & $1,13 \mathrm{ab}$ & $0,783 c$ & $0,471 \mathrm{~b}$ & $4,3 \mathrm{~b}$ & $3,9 \mathrm{a}$ \\
\hline $\mathrm{RCS}$ & $161,7 \mathrm{~b}$ & $113,5 \mathrm{~b}$ & $33,2 \mathrm{~b}$ & $20,1 b$ & $1,14 \mathrm{ab}$ & $1,07 \mathrm{ab}$ & $0,987 \mathrm{abc}$ & $0,596 \mathrm{ab}$ & $6,1 \mathrm{ab}$ & $5,2 \mathrm{a}$ \\
\hline $\mathrm{INC}$ & $154,7 \mathrm{~b}$ & $156,9 \mathrm{ab}$ & $37,8 \mathrm{~b}$ & $28,7 \mathrm{ab}$ & $1,11 \mathrm{ab}$ & $1,39 a b$ & $0,946 \mathrm{bc}$ & $0,600 \mathrm{ab}$ & $6,1 \mathrm{ab}$ & $3,8 \mathrm{a}$ \\
\hline $\mathrm{RCQ}$ & $136,3 \mathrm{~b}$ & $121,4 \mathrm{~b}$ & $34,5 b$ & $20,6 b$ & $0,81 b$ & $1,15 \mathrm{ab}$ & $1,046 \mathrm{abc}$ & $0,517 \mathrm{ab}$ & $7,7 \mathrm{a}$ & $4,2 \mathrm{a}$ \\
\hline
\end{tabular}

(1) AVN: área de vegetação natural de mata secundária, E11: área onde não foi realizado o corte das árvores do primeiro ciclo (eucalipto com 11 anos), RCM: reforma sem a remoção de resíduos (cultivo mínimo), RGC: reforma com remoção dos restos culturais (galhos e cascas), RCS: reforma com remoção dos restos culturais e da serapilheira, INC: reforma com incorporação de todos os resíduos com grade e RCQ: reforma com a queima de todos os resíduos. Médias seguidas pela mesma letra, na coluna, não diferem entre si pelo teste de Tukey a $5 \%$.

mesmo se os níveis do carbono orgânico permanecerem inalterados (Powlson et al., 1987).

O solo localizado na área RCQ apresentou o menor valor absoluto de $q \mathrm{MIC}$ na profundidade de 0 a $5 \mathrm{~cm}$, quando comparado aos demais solos sob eucalipto (Quadro 2). Esse fato demonstra o efeito adverso da queima também sobre esse indicador da qualidade do solo, corroborando resultados de outros estudos, que confirmam o forte e duradouro efeito do fogo sobre as comunidades microbianas do solo (Dumontet et al., 1996; Ross et al., 1997; Mabuhay et al., 2003). Contudo, a ausência de diferença significativa entre essa área e as demais áreas com povoamentos de eucalipto indica o restabelecimento do equilíbrio da relação entre o $\mathrm{C}$ microbiano e o $\mathrm{C}$ orgânico total, indicando, portanto, que o efeito adverso da queima dos resíduos sobre a comunidade microbiana do solo está sendo diluído ao longo do crescimento da floresta.

\section{Respiração basal e $q \mathrm{CO}_{2}$}

Os maiores valores de atividade respiratória basal foram encontrados nas áreas AVN (vegetação natural) e E11 (área com eucalipto, sem corte das árvores do primeiro ciclo) e os menores nas áreas RGC (reforma com remoção dos restos culturais - galhos e cascas), em ambas as profundidades, e na área RCM (reforma sem remoção de resíduos), na profundidade de 5 a $20 \mathrm{~cm}$ (Quadro 2). Nas áreas com povoamentos de eucalipto, foram encontradas diferenças significativas das taxas respiratórias na camada de $0-5 \mathrm{~cm}$; as áreas $\mathrm{RGC} \mathrm{e}$ INC (reforma com incorporação dos resíduos) apresentaram menor valor de respiração basal do que a área E11, que contém eucalipto com 11 anos. Os dados obtidos não podem ser explicados pelo tipo de manejo empregado nas áreas e parecem refletir variações ao acaso de fatores como queda de serapilheira, umidade e temperatura. Esse fato é comprovado pela ausência de efeito de manejo sobre a taxa respiratória nas áreas com eucalipto na camada de 5-20 cm, a qual tende a apresentar menor oscilação de temperatura e umidade e disponibilidade de substrato prontamente mineralizável. Conclui-se, portanto, que a taxa respiratória não foi um indicador eficaz para predição de efeito de uso ou manejo sobre a qualidade dos solos.

Os solos sob vegetação natural (área AVN) e sob eucalipto no qual a reforma foi realizada com a remoção dos restos culturais (área RGC) apresentaram os menores valores de $q \mathrm{CO}_{2}$ na profundidade de 0 a $5 \mathrm{~cm}$. Esses valores diferiram significativamente apenas da área $\mathrm{RCQ}$, em que foi realizada a reforma com a queima de todos os resíduos, a qual apresentou o maior valor. Esses resultados também demonstram o efeito do distúrbio causado pela queima sobre a biomassa microbiana, mesmo após 5,5 anos da aplicação desse manejo, refletido na baixa eficiência dos microrganismos em converter os resíduos orgânicos em biomassa microbiana, pois grande parte é mineralizada e devolvida à atmosfera na forma de $\mathrm{CO}_{2}$. 
O quociente metabólico $q \mathrm{CO}_{2}$ (Anderson \& Domsch, 1985) permite a identificação dos solos contendo biomassa mais eficiente na utilização de carbono e energia $\left(<q \mathrm{CO}_{2}\right)$ (Wardle \& Ghani, 1995), os quais refletem, de acordo com a teoria do "desenvolvimento bioenergético dos ecossistemas" de Odum (1969), ambientes com menor grau de distúrbio ou estresse. $\mathrm{O}_{q} \mathrm{CO}_{2}$ é considerado um indicador adequado em estudos de maturação progressiva do sistema solo (Anderson \& Domsch, 1990). Segundo Anderson \& Domsch (1993), valores mais elevados de $q \mathrm{CO}_{2}$ são normalmente associados com ecossistemas jovens (imaturos). Ao contrário, menores valores de $q \mathrm{CO}_{2}$ são normalmente associados com ecossistemas maduros e mais estáveis. Segundo essa concepção, o $q \mathrm{CO}_{2}$ na área de eucalipto com 11 anos (E11) deveria ser o mais próximo ao observado na área com vegetação nativa e mais baixo do que nas demais áreas com povoamentos de eucalipto mais jovens. Contudo, esse comportamento não foi o observado (Quadro 2), o que possivelmente está relacionado a um estresse nutricional imposto por baixa disponibilidade de nutrientes, ou pela elevada acidez nos solos estudados (Quadro 1), condições essas que tendem a reduzir a eficiência catabólica das populações microbianas (Böhme et al., 2005).

Na camada de 5-20 cm, não houve diferença do quociente metabólico entre as áreas estudadas. Uma possível explicação para este resultado é uma mudança das populações microbianas ao longo do perfil do solo, passando de uma predominância de estrategistas ' $r$ ' na camada mais superficial (favorecidos pela abundância de material facilmente decomponível) para de estrategistas ' $\mathrm{K}$ ', na camada de $5-20 \mathrm{~cm}$. Os estrategistas ' $\mathrm{K}$ ' são especialistas em decompor lentamente material orgânico mais estável e tendem a apresentar maior eficiência metabólica do que os estrategistas ' $r$ ' (Insam \& Hasselwandter, 1989). Recentemente, Rethemeyer et al. (2005), estudando a concentração de radiocarbono ao longo do perfil de solos na Alemanha, concluíram pelo enriquecimento progressivo de compostos orgânicos estáveis com o aumento da profundidade do solo, corroborando assim a sugestão de que, no presente estudo, uma mudança de estrategistas ' $r$ ' para estrategistas ' $\mathrm{K}$ ' tenha ocorrido entre as camadas de solo estudadas. Segundo Atlas \& Bartha (1998), embora apresentem alta taxa reprodutiva, os estrategistas ' $\mathrm{r}^{6}$ possuem poucas adaptações para competir com outras populações microbianas e para se adaptarem a flutuações ambientais, predominando em situações em que não haja limitações nutricionais. Por outro lado, os estrategistas ' $\mathrm{K}$ ' dependem de adaptações fisiológicas à capacidade-suporte do ambiente em que habitam, e suas populações tendem a ser mais estáveis. Essa maior capacidade de adaptação fisiológica e estabilidade dos estrategistas ' $\mathrm{K}$ ', os quais devem predominar na camada de 5-20 cm, é, portanto, uma explicação plausível para a ausência de efeito de uso ou manejo dos solos estudados sobre a eficiência metabólica dos microrganismos, nesta camada.

\section{Atividade de enzimas do solo}

As atividades de todas as enzimas do solo analisadas, à exceção da urease, apresentaram padrões de comportamento semelhantes, mostrando-se significativamente maiores no solo sob vegetação nativa, nas duas profundidades avaliadas (Quadro 3). Lazari (2001), também estudando características microbiológicas em solos sob eucalipto com diferentes idades e em um solo com vegetação nativa, observou que as atividades das enzimas $\beta$-glicosidase e das fosfatases ácida e alcalina também foram consistentemente maiores no solo sob vegetação natural.

Na camada de $0-5 \mathrm{~cm}$, foi encontrada correlação significativa entre o CBM e a atividade de fosfatase ácida $(\mathrm{r}=0,94 ; p<0,001)$ e alcalina $(\mathrm{r}=0,94$; $p<0,001)$. Igualmente, na camada de $5-20 \mathrm{~cm}$, as correlações foram significativas entre o CBM e a atividade de fosfatase ácida $(\mathrm{r}=0,97 ; p<0,001)$ e alcalina $(r=0,81 ; p<0,001)$. Esses resultados são coerentes com o fato de que as fosfatases originam-se predominantemente da biomassa microbiana (Klose \& Tabatabai, 2002).

Correlações significativas e positivas foram também encontradas entre o CBM e a atividade de desidrogenase $(r=0,93$ e 0,$87 ; p<0,001$ nas camadas de $0-5$ e $5-20 \mathrm{~cm}$, respectivamente) e â-glicosidase $(\mathrm{r}=0,94$ e 0,$96 ; p<0,001$ nas camadas de $0-5$ e $5-20 \mathrm{~cm}$, respectivamente). As correlações entre o CBM e a atividade de urease, embora também significativas, não foram tão elevadas quanto as reportadas para as demais enzimas $(\mathrm{r}=0,60$ e 0,$49 ; p<0,01$ nas camadas de $0-5$ e $5-20 \mathrm{~cm}$, respectivamente). Foram igualmente obtidas correlações positivas e significativas entre o teor de matéria orgânica e do NBM e as enzimas desidrogenase, $\beta$-glicosidase e urease (dados não apresentados). Correlações significativas entre essas variáveis têm sido reportadas em outros estudos (Landgraf \& Klose, 2002; Taylor et al., 2002; Turner et al., 2002; Böhme et al., 2005) e refletem o papel da biomassa microbiana na ciclagem dos nutrientes no solo.

A atividade de desidrogenase decresceu significativamente com a conversão do solo sob vegetação nativa para o cultivo de eucalipto (Quadro 3). Essa redução foi menos intensa na camada mais profunda. A desidrogenase é uma oxidorredutase, estando presente somente em células viáveis, e tem sido considerada um indicador sensível da qualidade do solo (Nannipieri, 1994), bem como um marcador capaz de indicar mudanças na atividade microbiana total em resposta a mudanças impostas pelo uso ou manejo do solo (Ceccanti et al., 1994; Roldán et al., 2005). A menor variação da atividade dessa enzima, na camada de 5-20 cm, é condizente com a menor variação do $q \mathrm{CO}_{2}$ nessa mesma camada e, igualmente, pode ser atribuída à predominância de estrategistas ' $\mathrm{K}$ ', cuja atividade é menos variável. 
Quadro 3. Atividade das enzimas desidrogenase, $\beta$-glicosidase, fosfomonoesterases ácida e alcalina e urease em amostras de solo sob plantio de eucalipto retiradas de parcelas submetidas a diferentes manejos culturais e de uma área com vegetação natural adjacente

\begin{tabular}{|c|c|c|c|c|c|c|c|c|c|c|}
\hline \multirow{2}{*}{ Área $^{(1)}$} & \multicolumn{2}{|c|}{ Desidrogenase } & \multicolumn{2}{|c|}{$\beta$-Glicosidase } & \multicolumn{2}{|c|}{ Fosfatase ácida } & \multicolumn{2}{|c|}{ Fosfatase alcalina } & \multicolumn{2}{|c|}{ Urease } \\
\hline & $0-5 \mathrm{~cm}$ & $5-20 \mathrm{~cm}$ & $0-5 \mathrm{~cm}$ & $5-20 \mathrm{~cm}$ & $0-5 \mathrm{~cm}$ & $5-20 \mathrm{~cm}$ & $0-5 \mathrm{~cm}$ & $5-20 \mathrm{~cm}$ & $0-5 \mathrm{~cm}$ & $5-20 \mathrm{~cm}$ \\
\hline & \multicolumn{2}{|c|}{$-\mu \mathrm{mol} \mathrm{kg}{ }^{-1} \mathrm{~h}^{-1}$ de TFF -} & 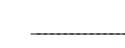 & $\mathrm{m}$ & $\mathrm{kg}^{-1} \mathrm{~h}^{-1}$ & $\boldsymbol{p}$-nitrofer & $\mathrm{ol}$ & $\underline{-}$ & \multicolumn{2}{|c|}{$\mathrm{mmol} \mathrm{kg}^{-1} \mathrm{~h}^{-1} \mathrm{de} \mathrm{NH}_{4}^{+}$} \\
\hline AVN & $348,1 \mathrm{a}$ & $54,0 \mathrm{a}$ & $69,5 \mathrm{a}$ & $41,9 \mathrm{a}$ & $421,2 \mathrm{a}$ & $165,1 \mathrm{a}$ & $71,6 \mathrm{a}$ & $16,2 \mathrm{a}$ & $2,11 \mathrm{a}$ & $2,05 \mathrm{a}$ \\
\hline E11 & $54,5 \mathrm{~b}$ & $21,9 \mathrm{~b}$ & $45,9 \mathrm{~b}$ & $25,7 \mathrm{~b}$ & $223,7 \mathrm{~b}$ & $103,0 \mathrm{~b}$ & $29,9 \mathrm{~b}$ & $12,4 \mathrm{ab}$ & $1,81 \mathrm{a}$ & $1,86 a b$ \\
\hline $\mathrm{RCM}$ & $108,0 \mathrm{~b}$ & $29,1 b$ & $50,1 \mathrm{ab}$ & $18,2 \mathrm{~b}$ & $179,3 \mathrm{~b}$ & $77,1 \mathrm{bc}$ & $24,7 \mathrm{~b}$ & $8,0 \mathrm{~b}$ & $1,54 \mathrm{a}$ & $2,10 \mathrm{a}$ \\
\hline $\mathrm{RGC}$ & $76,1 \mathrm{~b}$ & $28,0 \mathrm{~b}$ & $46,5 b$ & $18,5 b$ & $175,5 b$ & $82,0 \mathrm{bc}$ & $30,0 \mathrm{~b}$ & $9,6 \mathrm{~b}$ & $1,39 \mathrm{a}$ & $1,59 \mathrm{ab}$ \\
\hline $\mathrm{RCS}$ & $70,8 b$ & $21,7 \mathrm{~b}$ & $42,8 \mathrm{~b}$ & $15,9 \mathrm{~b}$ & $146,6 \mathrm{~b}$ & $73,3 \mathrm{c}$ & $24,3 \mathrm{~b}$ & $9,6 \mathrm{~b}$ & $1,55 \mathrm{a}$ & $1,35 \mathrm{ab}$ \\
\hline INC & $74,5 b$ & $33,8 \mathrm{~b}$ & $44,4 \mathrm{~b}$ & $23,5 b$ & $174,7 \mathrm{~b}$ & $99,9 \mathrm{bc}$ & $23,1 b$ & $8,4 \mathrm{~b}$ & $1,52 \mathrm{a}$ & $1,69 a b$ \\
\hline $\mathrm{RCQ}$ & $51,4 \mathrm{~b}$ & $24,6 \mathrm{~b}$ & $44,6 \mathrm{~b}$ & $14,9 \mathrm{~b}$ & $154,2 \mathrm{~b}$ & $74,4 \mathrm{c}$ & $25,7 \mathrm{~b}$ & $7,9 \mathrm{~b}$ & $1,80 \mathrm{a}$ & $1,06 \mathrm{~b}$ \\
\hline
\end{tabular}

TFF: trifenil formazan.

(1) AVN: área de vegetação natural de mata secundária, E11: área onde não foi realizado o corte das árvores do primeiro ciclo (eucalipto com 11 anos), RCM: reforma sem a remoção de resíduos (cultivo mínimo), RGC: reforma com remoção dos restos culturais (galhos e cascas), RCS: reforma com remoção dos restos culturais e da serapilheira, INC: reforma com incorporação de todos os resíduos com grade e RCQ: reforma com a queima de todos os resíduos. Médias seguidas pela mesma letra, na coluna, não diferem entre si pelo teste de Tukey a $5 \%$.

As hidrolases do solo são enzimas relacionadas com a mineralização de nutrientes essenciais aos ecossistemas terrestres, a exemplo do $\mathrm{N}$, do $\mathrm{S}$, do $\mathrm{C} \mathrm{e}$ do P. Desse modo, a avaliação da atividade das hidrolases em solos propicia uma indicação precoce do seu estado nutricional. A menor atividade das hidrolases, especialmente da $\beta$-glicosidase e das fosfatases acida e alcalina nos solos utilizados para cultivo de eucalipto, é uma indicação de que a nutrição tanto das plantas quanto dos microrganismos do solo, nessas áreas, está ligada mais ao "pool” de nutrientes presentes na solução do solo, o que tende a promover perdas de elementos essenciais nessas áreas.

Não foram detectadas diferenças significativas de atividade enzimática entre as áreas com plantios de eucalipto, exceto da fosfatase ácida na camada de 5 a $20 \mathrm{~cm}$. Tanto a retirada (área RCS) quanto a queima dos resíduos culturais (área RCQ) promoveram redução significativa da atividade de fosfatase ácida em relação à área $\mathrm{E} 11$, que contém floresta de eucalipto com 11 anos de idade.

\section{Taxas de nitrificação e de amonificação líquidas}

Os valores médios obtidos para as taxas de amonificação e de nitrificação líquidas na profundidade de 0 a $5 \mathrm{~cm}$ para os solos sob eucalipto com 5,5 anos (áreas RCM, RGC, RCS, INC e RCQ) foram de $0,49 \mathrm{mg} \mathrm{kg}^{-1} \mathrm{~d}^{-1} \mathrm{de} \mathrm{N}^{-\mathrm{NH}_{4}}{ }^{+}$e de $0,36 \mathrm{mg} \mathrm{kg}^{-1} \mathrm{~d}^{-1} \mathrm{de}$ $\mathrm{N}-\mathrm{NO}_{3}{ }^{-}$(Quadro 4), semelhantemente aos encontrados por Lazari (2001) em solos argilosos sob plantio de eucalipto aos cinco anos de idade. A maior taxa de amonificação líquida foi encontrada no solo sob vegetação natural (área AVN) e a menor na área de manejo do eucalipto em que foi realizada a queima dos restos culturais e da serapilheira (área RCQ), na profundidade de 0 a $5 \mathrm{~cm}$. Esse resultado demonstra a sensibilidade desse indicador a alterações no solo resultantes de uso e manejo e, à semelhança de outros resultados já apresentados, atesta o impacto da utilização do fogo sobre a qualidade do solo estudado. Contudo, assim como observado para o qMIC (Quadro 2), a taxa de amonificação não foi capaz de discriminar efeito de manejo nas áreas com eucalipto. Isso sugere que em culturas de ciclos mais longos, como o eucalipto, os efeitos de manejo impostos por ocasião da implantação do povoamento florestal sobre a qualidade do solo são dissipados ao longo do crescimento da floresta. Não é possível antecipar, com base nos resultados deste trabalho, que ciclos sucessivos de cultivo de eucalipto utilizando manejos mais drásticos, como a queima ou a retirada dos resíduos, não irão resultar na degradação do solo. Por outro lado, a redução consistente dos valores absolutos da maioria dos indicadores microbiológicos avaliados neste estudo, na área em que se empregou a queima dos resíduos, indica que a repetição de ciclos de cultivo empregando-se esse manejo pode levar a uma redução mais acentuada da qualidade do solo. Na profundidade de 5 a $20 \mathrm{~cm}$, a taxa de amonificação líquida discriminou somente as áreas RGC (reforma com remoção de galhos e cascas) e INC (reforma com incorporação de todos os resíduos com grade), não podendo essa diferença ser explicada pelo manejo 
Quadro 4. Taxa de nitrificação e de amonificação em amostras de solo sob plantio de eucalipto retiradas de parcelas submetidas a diferentes manejos culturais e de uma área com vegetação natural adjacente

\begin{tabular}{|c|c|c|c|c|}
\hline \multirow{2}{*}{$\operatorname{Área}^{(1)}$} & \multicolumn{2}{|c|}{ Taxa de nitrificação } & \multicolumn{2}{|c|}{ Taxa de amonificação } \\
\hline & $0-5 \mathrm{~cm}$ & $5-20 \mathrm{~cm}$ & $0-5 \mathrm{~cm}$ & $5-20 \mathrm{~cm}$ \\
\hline & \multicolumn{2}{|c|}{ - mg kg ${ }^{-1} \mathrm{~d}^{-1}$ de $\mathrm{N}-\mathrm{NO}_{3}{ }^{-}$no solo - } & \multicolumn{2}{|c|}{$-\mathrm{mg} \mathrm{kg}^{-1} \mathrm{~d}^{-1} \mathrm{de} \mathrm{N}-\mathrm{NH}_{4}{ }^{+}$no solo -} \\
\hline AVN & $0,450 \mathrm{a}$ & $0,216 \mathrm{a}$ & $0,602 \mathrm{a}$ & $0,348 \mathrm{ab}$ \\
\hline E11 & $0,195 b$ & $0,164 \mathrm{a}$ & $0,426 \mathrm{ab}$ & $0,287 \mathrm{~b}$ \\
\hline $\mathrm{RCM}$ & $0,426 \mathrm{ab}$ & $0,092 \mathrm{a}$ & $0,503 \mathrm{ab}$ & $0,275 \mathrm{~b}$ \\
\hline RGC & $0,451 \mathrm{a}$ & $0,164 \mathrm{a}$ & $0,572 \mathrm{ab}$ & $0,444 \mathrm{a}$ \\
\hline $\mathrm{RCS}$ & $0,325 \mathrm{ab}$ & $0,141 \mathrm{a}$ & $0,491 \mathrm{ab}$ & $0,328 \mathrm{ab}$ \\
\hline INC & $0,318 \mathrm{ab}$ & $0,134 \mathrm{a}$ & $0,531 \mathrm{ab}$ & $0,219 b$ \\
\hline $\mathrm{RCQ}$ & $0,297 \mathrm{ab}$ & $0,115 \mathrm{a}$ & $0,360 \mathrm{~b}$ & $0,294 \mathrm{ab}$ \\
\hline
\end{tabular}

\begin{abstract}
(1) AVN: área de vegetação natural de mata secundária, E11: área onde não foi realizado o corte das árvores do primeiro ciclo (eucalipto com 11 anos), RCM: reforma sem a remoção de resíduos (cultivo mínimo), RGC: reforma com remoção dos restos culturais (galhos e cascas), RCS: reforma com remoção dos restos culturais e da serapilheira, INC: reforma com incorporação de todos os resíduos com grade e RCQ: reforma com a queima de todos os resíduos. Médias seguidas pela mesma letra, na coluna, não diferem entre si pelo teste de Tukey a $5 \%$.
\end{abstract}

empregado nessas áreas nem pela análise das demais variáveis estudadas.

As taxas de nitrificação líquida obtidas neste trabalho (Quadro 4) contradizem, de certa forma, as afirmações de alguns autores (Rice \& Pancholy, 1972; Robertson, 1982; Davidson et al., 1992) de que o processo de nitrificação tende a ser menos expressivo em comunidades microbianas mais evoluídas e equilibradas. À exceção do solo da área E11, os solos que deveriam, segundo essa linha de pensamento, apresentar taxas menores de nitrificação, como o da área com vegetação natural (área AVN) e os solos sob cultivo de eucalipto com manejos mais conservadores (áreas RCM e RGC), apresentaram as maiores taxas de nitrificação na profundidade de 0 a $5 \mathrm{~cm}$. Já os solos das áreas RCS, INC e RCQ, que a princípio receberam os tratamentos menos conservadores, apresentaram as menores taxas de nitrificação nessa profundidade. Essa aparente contradição também é expressa nos resultados encontrados por Lazari (2001), a qual observou que a taxa de nitrificação líquida aumentou com o avanço da idade da vegetação em florestas de eucalipto em Minas Gerais, sendo os maiores valores detectados na área com vegetação natural adjacente aos plantios de eucalipto. Aparentemente, nas áreas cujo manejo levou à retirada dos resíduos orgânicos da superfície (áreas RCS, INC e RCQ), a taxa de nitrificação na camada de $0-5 \mathrm{~cm}$ foi reduzida por limitação de substrato, uma vez que foi encontrada correlação positiva significativa entre a taxa de nitrificação e a de amonificação $(r=0,75$; $p<0,001)$. Na área com eucalipto com 11 anos (área E11), a baixa taxa de nitrificação pode ser igualmente resultante da limitação de substrato, mas, também, do maior acúmulo de compostos inibitórios às populações de microrganismos nitrificantes pela deposição de serapilheira.

Rice \& Pancholy (1972) propuseram que a atividade de populações de microrganismos nitrificantes é de algum modo inibida por substância(s) exsudada(s) pela vegetação presente em comunidades clímax, principalmente taninos (Rice \& Pancholy, 1973), ou outras substâncias potencialmente inibidoras de Nitrosomonas, como os compostos fenólicos e flavonóides (Rice \& Pancholy, 1974) e os monoterpenos (Paavolainen et al., 1998).

A inibição da nitrificação traz implicações importantes na ciclagem e conservação do nitrogênio nos ecossistemas. Dois passos bioquímicos que requerem uma energia considerável - a redução do nitrato a nitrito e de nitrito a nitrogênio amoniacal são eliminados. A inibição da nitrificação resulta, assim, em conservação de energia. Quando são consideradas a conservação do nitrogênio, a conservação de energia e a habilidade de muitas espécies vegetais em usar o amônio mais eficientemente que o nitrato, não é surpreendente que a sucessão caminhe no sentido de inibir a nitrificação (Rice \& Pancholy, 1972). Esta hipótese já havia sido sugerida por Warren (1965), citado por Robertson \& Vitousek (1981), em estudos em solos africanos. Resultados semelhantes e condizentes com a hipótese supracitada foram obtidos por Todd et al. (1975) e por Lodhi et al. (1979) em solos norteamericanos. Vogt \& Edmonds (1977) sugeriram, assim como Rice \& Pancholy $(1973,1974)$, que a inibição da nitrificação em solos sob floresta é de origem química. 
Por outro lado, experimentos realizados por Robertson \& Vitousek (1981) não validaram a hipótese da inibição da nitrificação ao longo do processo de sucessão vegetal. Estes autores observaram que a maior parte do $\mathrm{N}$ mineral foi transformada em nitrato em quase todas as áreas, sugerindo que a taxa de nitrificação possa ser controlada pela taxa de mineralização do nitrogênio. Esse fato é coerente com a elevada correlação positiva entre as taxas de amonificação e nitrificação encontrada neste trabalho. Finalmente, segundo Bauhus et al. (1993), a baixa população de nitrificantes em condições ácidas pode ser o fator limitante para uma alta taxa de nitrificação. Esses autores observaram aumento da concentração de nitrato em solos ácidos sob eucalipto na Austrália, após inoculação de microrganismos nitrificantes. Na ausência de inoculação, os nitrificantes existentes nos solos foram estimulados pela calagem e pela adição de $\mathrm{P}$. Os autores sugerem que o baixo $\mathrm{pH}$ não é um fator limitante para a nitrificação, mas um $\mathrm{pH}$ mais próximo à neutralidade pode promover o estabelecimento de populações de nitrificantes autotróficos.

\section{Análise de componentes principais (ACP)}

A ACP realizada a partir das variáveis químicas, físicas e microbiológicas selecionadas permitiu agrupar nos dois primeiros componentes principais (CPs) $79,1 \%$ da variância total para profundidade de 0 a $5 \mathrm{~cm}$ e 79,6 \% da variância total na profundidade de 5 a $20 \mathrm{~cm}$. A dispersão dos escores obtidos para cada uma das áreas, em um sistema de eixos cartesianos representados pelos dois primeiros CPs, permitiu visualizar as semelhanças e diferenças entre as áreas com base nas variáveis analisadas (Figura 1a,b). A área com vegetação natural (AVN), usada como referência de qualidade do solo, foi a que apresentou a maior distância gráfica das demais áreas em ambas as profundidades, demonstrando que a introdução da monocultura do eucalipto alterou significativamente a qualidade do solo.

Dentre os solos amostrados sob eucalipto submetidos a diferentes manejos, na profundidade de 0 a $5 \mathrm{~cm}$ (Figura 1a), identificam-se pelo menos três comportamentos ou padrões quanto à qualidade do solo: a área $\mathrm{E} 11$, onde não foi feito o corte das árvores do primeiro ciclo, foi o ponto com menor valor no segundo componente principal (C2); as áreas RCM (reforma sem a remoção de resíduos) e RGC (reforma com remoção dos restos culturais e manutenção da serapilheira) foram os pontos com maiores valores no $\mathrm{C} 2$; e as áreas RCQ (reforma com a queima dos resíduos), RCS (reforma com remoção dos restos culturais e da serapilheira) e INC (reforma com incorporação dos resíduos com grade) situaram-se em uma posição intermediária em relação ao C2. Esse agrupamento subjetivo separa, com relação às características avaliadas do solo, as áreas com manejos mais contrastantes, como a área $\mathrm{E} 11$, em que o povoamento de eucalipto se encontrava com 11 anos, das demais áreas, em que o povoamento se encontrava com 5,5 anos. Da mesma forma, as áreas RCM e RGC, que proporcionaram a manutenção de resíduos orgânicos na superfície do solo, diferenciaram-se das áreas RCS, INC e RCQ, as quais sofreram a retirada, incorporação e queima, respectivamente, dos restos culturais e da serapilheira.

A figura 1a mostra ainda a projeção dos pontos no eixo $\mathrm{X}$, que corresponde aos escores de cada área referente ao primeiro componente principal (C1), o qual explica a maior parcela da variância dos dados $(58,5 \%)$. Considerando a área AVN como referência de qualidade, pode-se constatar, pela projeção dos pontos, que o manejo E11 é o que mais se aproxima dessa referência, seguido pelos manejos RCM, RGC, INC, RCS e RCQ. Por meio desse critério, os manejos relacionados às áreas RCS, INC e RCQ podem ser considerados como os que causaram a maior modificação em relação à vegetação natural, sendo justamente aqueles que, em teoria, causam os maiores distúrbios ou perdas de energia do sistema, como a gradagem (área INC) e a retirada ou queima de todo o material orgânico (áreas RCS e RCQ). Por outro lado, infere-se que as áreas RCM e RGC, onde o manejo priorizou a manutenção dos resíduos orgânicos na área, apresentaram menor grau de distúrbio quando
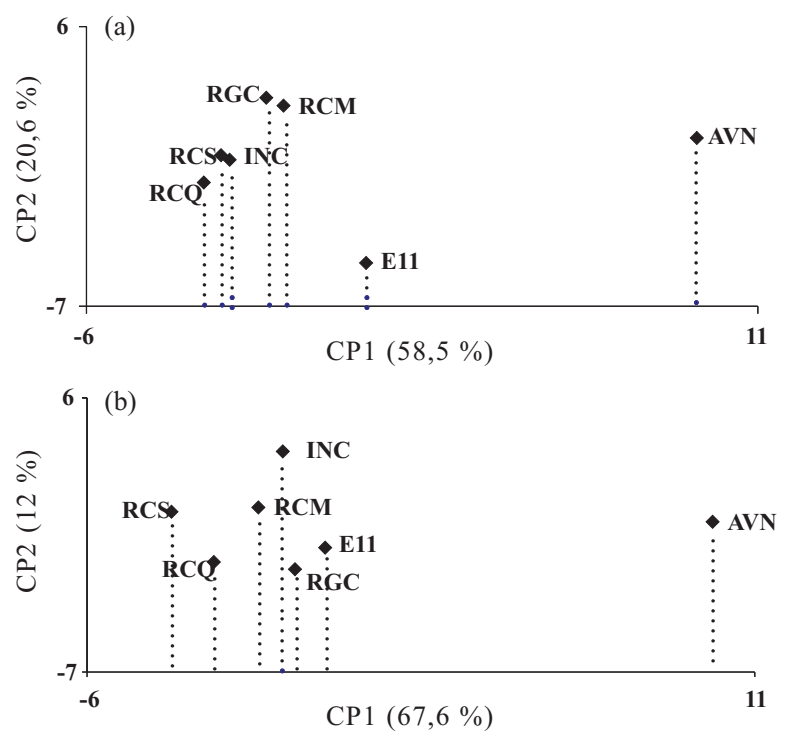

Figura 1. Dispersão dos escores das áreas estudadas em relação aos dois primeiros CPs, tendo como base as variáveis medidas a partir de amostras de solo das camadas de 0 a $5 \mathrm{~cm}$ (a) e 5 a $20 \mathrm{~cm}$ (b) de profundidade. AVN: área de vegetação natural de mata secundária, E11: área onde não foi realizado o corte das árvores do primeiro ciclo (eucalipto com 11 anos), RCM: reforma sem a remoção de resíduos (cultivo mínimo), RGC: reforma com remoção dos restos culturais (galhos e cascas), RCS: reforma com remoção dos restos culturais e da serapilheira, INC: reforma com incorporação de todos os resíduos com grade e RCQ: reforma com a queima de todos os resíduos. 
se coloca o solo sob vegetação natural como referencial de qualidade. Esse fato demonstra que o cultivo mínimo favorece a conservação do solo e, portanto, deve ser considerado como o mais sustentável em longo prazo, pois, entre outros aspectos, contribui para manutenção dos nutrientes no sistema (Gatto, 2000).

A maior proximidade entre a área E11 (eucalipto com 11 anos) e a área AVN (referência), resultado que pode ser observado também para a profundidade de 5 a $20 \mathrm{~cm}$ (Figura 1b), pode ser interpretada como uma tendência da floresta de eucalipto em aproximar o seu estado qualitativo daquele alcançado pela vegetação natural com o avanço da idade do povoamento. Essa recuperação do fator qualidade em solos sob eucalipto com o avanço da idade do povoamento também foi constatada em solos argilosos (Lazari, 2001). Essa observação leva a supor que ciclos mais longos nas florestas de eucalipto, contrastando com o padrão atualmente em uso no Brasil (cerca de sete anos), podem ser relevantes para manter a sustentabilidade da atividade florestal em longo prazo, a despeito de uma menor produtividade média anual.

A projeção dos escores obtidos para a profundidade de 5 a $20 \mathrm{~cm}$ no $\mathrm{C} 1$, que representa $67,6 \%$ da variância (Figura 1b), mostrou um padrão semelhante ao obtido para a profundidade de 0 a $5 \mathrm{~cm}$, exceto pelo deslocamento da área INC em direção à área AVN. Esse fato pode ser explicado pela melhoria causada nessa profundidade pela incorporação da serapilheira e dos restos culturais, levando a um incremento na biomassa e atividade microbianas nessa camada.

A figura 2 mostra a dispersão dos autovalores das variáveis utilizadas na ACP em relação aos dois primeiros CPs, nas profundidades de 0 a $5 \mathrm{~cm}$ (A) e de 5 a $20 \mathrm{~cm}$ (B). Esses gráficos demonstram o relacionamento entre as variáveis analisadas e como elas influenciaram a ordenação das áreas mostrada na figura 1. Observa-se que a separação entre as áreas em relação ao $\mathrm{CP} 1$, em ambas as camadas de solo, foi inequivocamente influenciada pela presença de dois conjuntos de variáveis inversamente correlacionados. $\mathrm{O}$ primeiro conjunto, à direita, agrupa a maioria das características microbiológicas e bioquímicas do solo, além das características químicas associadas à acidez do solo, como o teor de $\mathrm{Al}^{3+}$, a acidez potencial $(\mathrm{H}+\mathrm{Al})$ e a percentagem de saturação por alumínio

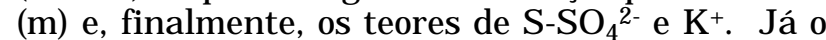
segundo conjunto, à esquerda, agrupou, à exceção do quociente metabólico $\left(q \mathrm{CO}_{2}\right)$, exclusivamente características químicas e físicas do solo, como $\mathrm{pH}$, teores de Ca, Mg e P, soma (SB) e saturação de bases (V) e densidade (D) (somente para a camada de 0 a $5 \mathrm{~cm}$ ). Dessa forma, pode-se concluir que áreas deslocadas mais à direita, como a área AVN (Figura 1), caracterizam-se por apresentar solos com elevada acidez e menores estoques de nutrientes na forma prontamente utilizável pelas plantas. Entretanto, possuem também maior reserva de nutrientes na biomassa e maior potencial de ciclagem de nutrientes, sendo caracte- rizadas pelos elevados valores de biomassa microbiana e atividade de enzimas do solo. Já as áreas deslocadas à esquerda (áreas com cultivo de eucalipto) (Figura 1) apresentam o comportamento inverso em diferentes graus de intensidade. Essa observação explica a forte distinção entre os solos da área de vegetação natural quando comparados aos solos sob eucalipto, comprovando que a introdução da monocultura causou alteração da qualidade biológica do solo, expressa pelos indicadores microbiológicos, enquanto houve ligeira melhora em algumas características químicas do solo, por influência das adubações realizadas durante a reforma do povoamento.

$\mathrm{O}$ alto grau de correlação entre grande número das variáveis analisadas, em especial das biológicas (Figura 2a,b), demonstra a alta redundância de
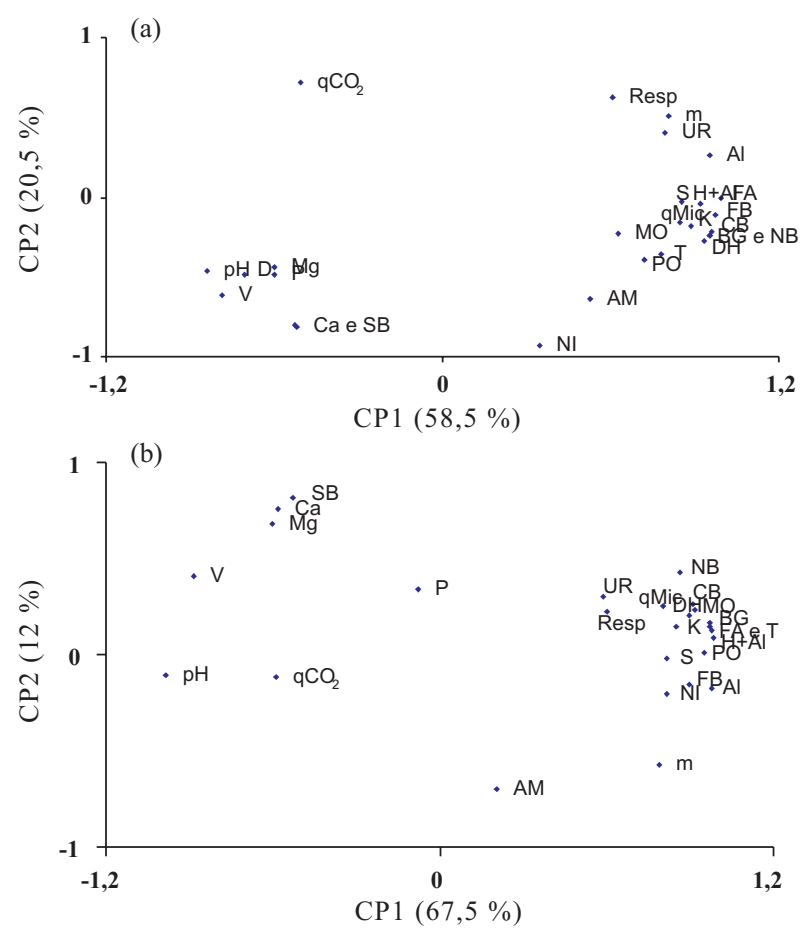

Figura 2. Dispersão dos autovalores das variáveis utilizadas na ACP em relação aos dois primeiros CPs, nas profundidades de 0 a $5 \mathrm{~cm}$ (a) e de 5 a $20 \mathrm{~cm}$ (b). CB: carbono da biomassa microbiana; NB: nitrogênio da biomassa microbiana; Resp: taxa de respiração basal; $q \mathrm{CO}_{2}$ : quociente metabólico (R/CB); qMIC: quociente microbiano (CB/C-orgânico); UR: ativ. urease; BG: ativ. $\beta$-glicosidase; FA: ativ. fosfomonoesterases ácidas; FB: ativ. fosfomonoesterases ácidas; DH: ativ. desidrogenases; NI: taxa de nitrificação; $\mathrm{AM}$ : taxa de amonificação; PO: fósforo orgânico; MO: matéria orgânica; pH: medido em CaCl; P: teor de fósforo inorgânico disponível; S: teor de enxofre (S-SO ${ }_{4}$; K, Ca, Mg, Al: bases; H + Al: acidez potencial; SB: soma de bases; T: CTC potencial (pH 7); V: saturação por bases; m: saturação por alumínio; D: densidade do solo. 
informação gerada por essas variáveis, o que leva a crer que seja dispensável a avaliação de todas elas para discriminar a qualidade do solo das áreas avaliadas. Com base nessa informação, é possível selecionar um conjunto menor de indicadores que representem as principais funções ecológicas do solo. Como exemplo, existe alta correlação entre os conteúdos de $\mathrm{C}$ e $\mathrm{N}$ na biomassa microbiana e entre as enzimas $\beta$-glicosidase, desidrogenases e fosfatases ácida e alcalina, os quais se constituem em indicadores de qualidade relacionados à função do solo de ciclar e armazenar nutrientes. Algumas dessas variáveis podem, por conseguinte, ser eliminadas, levando-se em conta os custos e a praticidade da determinação analítica do indicador, sem perda da informação acerca da qualidade do solo.

\section{CONCLUSÕES}

1. Dentre os 18 atributos químicos e físicos avaliados, apenas os teores de $\mathrm{K}^{+}$e o $\mathrm{P}$ orgânico do solo foram capazes de diferenciar solo sob vegetação nativa daqueles sob plantio de eucalipto. Entretanto, todos os 12 indicadores bioquímicos e microbiológicos avaliados foram capazes de mostrar essa diferença entre a área com vegetação nativa e pelo menos uma das áreas com eucalipto.

2. Dentre os indicadores microbiológicos estudados, os mais sensíveis a efeito de uso (vegetação natural $\mathrm{x}$ eucalipto) ou manejo do solo nas áreas com eucalipto foram o nitrogênio da biomassa microbiana e a atividade das enzimas desidrogenase, $\beta$-glicosidase, fosfatase ácida e fosfatase alcalina.

3. A análise de componentes principais evidenciou que, quanto à qualidade dos solos, as áreas submetidas a sistemas de implantação que prezam a manutenção da camada orgânica do solo agrupam-se mais próximas da área referência de qualidade, contendo a vegetação nativa; ao contrário, áreas submetidas a sistemas de preparo que resultam na perda da camada orgânica apresentam-se graficamente distantes da área de referência, sugerindo perda de qualidade nesses solos.

4. A elevada correlação entre vários atributos microbiológicos indica a possibilidade de se selecionar um conjunto reduzido de indicadores capaz de expressar a qualidade biológica dos solos, tornando sua adoção como rotina uma perspectiva atraente.

\section{LITERATURA CITADA}

ALVAREZ V., V.H.; NOVAIS, R.F.; BARROS, N.F.; CANTARUTTI, R.B. \& LOPES, A.S. Interpretação dos resultados das análises de solos. In: RIBEIRO, A.C.; GUIMARÃES, P.T.G. \& ALVAREZ V., V.H., eds. Recomendações para o uso de corretivos e fertilizantes em Minas Gerais - $5^{\text {a }}$ Aproximação. Viçosa, MG, Comissão de Fertilidade do Solo do Estado de Minas Gerais, 1999. p.25-32.
ANDERSON, T.H. \& DOMSCH, K.H. Ratios of microbial biomass carbon to total organic carbon in arable soils. Soil Biol. Biochem., 21:471-479, 1989.

ANDERSON, J.M. \& INGRAM, J.S.I. Tropical soil biology and fertility: A handbook of methods. 2.ed. Wallingford, CAB International, 1996. 221p.

ANDERSON, T.H. \& DOMSCH, K.H. Application of ecophysiological quotients $\left(q \mathrm{CO}_{2}\right.$ and $\left.q \mathrm{D}\right)$ on microbial biomasses from soils of different cropping histories. Soil Biol. Biochem., 22:251-255, 1990.

ANDERSON, T.H. \& DOMSCH, K.H. Determination of ecophysiological maintenance carbon requirements of soil microorganisms in a dormant state. Biol. Fert. Soils, 1:8189, 1985.

ANDERSON, T.H. \& DOMSCH, K.H. The metabolic quotient for $\mathrm{CO}_{2}\left(q \mathrm{CO}_{2}\right)$ as a specific activity parameter to assess the effects of environmental conditions, such as $\mathrm{pH}$, on the microbial biomass of forest soils. Soil Biol. Biochem., 25:393-395, 1993.

ATLAS, R.M. \& BARTHA, R. Microbial ecology: Fundamentals and applications. 4.ed. California, Benjamin/Cummings, 1998. 694p.

BAUHUS, J.; KHANNA, P.K. \& RAISON, R.J. Mineralization and nitrification in an Australian forest soil. Aust. J. Soil Res., 31:621-639, 1993.

BEHERA, N. \& SAHANI, U. Soil microbial biomass and activity in response to Eucalyptus plantation and natural regeneration on tropical soil. For. Ecol. Manag., 174:1-11, 2003.

BENDING, G.D.; TURNER, M.K.; RAYNS, F.; MARX, M.C. \& WOOD, M. Microbial and biochemical soil quality indicators and their potential for differentiating areas under contrasting agricultural management regimes. Soil Biol. Biochem., 36:1785-1792, 2004.

BETTANY, J.R.; STEWART, J.W.B. \& SAGGAR, S.K. The nature and forms of sulfur in organic matter fractions of soil selected along an environmental gradient. Soil Sci. Soc. Am. Proc., 43:981-985, 1979.

BÖHME, L.; LANGER, U. \& BÖHME, F. Microbial biomass, enzyme activities and microbial community structure in two European long-term field experiments. Agric. Ecosys. Environm., 109:141-152, 2005.

BOWMAN, R.A.; REEDER, J.D. \& LOBER, R.W. Changes in soil properties in a central plains rangeland soil after 3 , 20, and 60 years of cultivation. Soil Sci., 150:851-857, 1990.

BRAGA, J.M. \& DEFELIPO, B.V. Determinação espectrofotométrica de fósforo em extrato de solos e material vegetal. R. Ceres, 21:73-85, 1974.

BURGER, J.A. Limitations of bioassays for monitoring forest soil productivity: Rationale and example. Soil Sci. Soc. Am. J., 60:1674-1678, 1996.

CECCANTI, B.; PEZZAROSSA, B.; GALLARDO-LANCHO, F.J. \& MASCIANDARO, G. Bio-tests as markers of soil utilization and fertility. Geomicrobiol. J., 11:309-316, 1994.

DAVIDSON, E.A.; HART, S.C. \& FIRESTONE, M.K. Internal cycling of nitrate in soils of a mature coniferous forest. Ecology, 73:1148-1156, 1992. 
DORAN, J.W. \& PARKIN, T.B. Defining and assessing soil quality. In: DORAN, J.W.; COLEMAN, D.C.; BEZDICEK, D.F. \& STAWART, B.A., eds. Defining soil quality for a sustainable environment. Madison, ASA/SSSA, 1994. p.321. (Special Publication, 35)

DUMONTET, S.; DINEL, H.; SCOPA, A.; MAZZATURA, A. \& SARACINO, A. Post-fire soil microbial biomass and nutrient content of a pine forest soil from a dunal mediterranean environment. Soil Biol. Biochem., 28:14671475,1996

EIVAZI, F. \& TABATABAI, M.A. Glucosidases and galactosidases in soils. Soil Biol. Biochem., 20:601-606, 1988.

EMPRESA BRASILEIRA DE PESQUISA AGROPECUÁRIA EMBRAPA. Manual de métodos de análise de solo. Rio de Janeiro, 1997. 212p.

EMPRESA BRASILEIRA DE PESQUISA AGROPECUÁRIA EMBRAPA. Manual de análises químicas de solos, plantas e fertilizantes. Brasília, 1999. 370p.

EUCLYDES, R.F. SAEG - Sistema para Análises Estatísticas. versão 8.1. Viçosa, MG, Universidade Federal de Viçosa, 2003. (www.saeg.com.br)

GAMA-RODRIGUES, E.F.; GAMA-RODRIGUES, A.C. \& BARROS, N.F. Biomassa microbiana de carbono e de nitrogênio de solos sob diferentes coberturas florestais R. Bras. Ci. Solo, 21:361-365, 1997.

GATTO, A. Manejo do solo em áreas de reforma de floresta de eucalipto e seus reflexos na produtividade. Viçosa, MG, Universidade Federal de Viçosa, 2000. 62p. (Tese de Mestrado)

HART, S.C.; STARK, J.M.; DAVIDSON, E.A. \& FIRESTONE, M.K. Nitrogen mineralization, immobilization and nitrification. In: WEAVER, R.W.; AUGLE, S.; BOTTOMLY, P.J.; BEZDICEK, D.; SMITH, S. TABATABAI, A. \& WOLLUM, A., eds. Methods of soil analysis. Part 2. Microbiological and biochemical properties. Madison, SSSA, 1994. p.985-1018.

INSAM, H. \& HASSELWANDTER, K. Metabolic quotient of the soil microflora in relation to plant succession. Oecologia, 79:174-178, 1989.

INSAM, H.; MITCHELL, C.C. \& DORMAAR, J.F. Relationship of soil microbial biomass and activity with fertilization practice and crop yield of three ultisols. Soil Biol. Biochem., 23:459-464, 1991.

ISERMEYER, H. Eine einsache Metode zur Destimmung der Bodenatmung und der Karbonate im Boden. Z. Pflanzenernäh Bodenk., 56:26-38, 1952.

ISLAM, K.R. \& WEIL, R.R. Microwave irradiation of soil for routine measurement of microbial biomass carbon. Biol. Fert. Soils, 27:408-416, 1998.

JOERGENSEN, R.G. \& BROOKES, P.C. Ninhydrin-reactive nitrogen measurements of microbial biomass in $0,5 \mathrm{M}$ $\mathrm{K}_{2} \mathrm{SO}_{4}$ soils extracts. Soil Biol. Biochem., 22:1129-1136, 1990 .

KANDELER，E.; MARGESIN，R.; ÖHLINGER，R. \& SCHINNER, F. Bodenmikrobiologisches MonitoringVorschläge für eine Bodenzustandsinventur. Die Bodenk., 44:357-377, 1993.
KELTING, D.L.; BURGER, J.A.; PATTERSON, S.C.; AUST, W.M.; MIWA, M. \& TRETTIN, C.C. Soil quality assessment in domesticated forests - a southern pine example. For. Ecol. Manag., 122:167-185, 1999.

KEMPERS, A.J. \& ZWEERS, A. Ammonium determination in soils extracts by the salicylate methods. Comm. Soil Sci. Plant Anal., 17:715-723, 1986.

KENNEDY, A.C. \& PAPENDICK, R.I. Microbial characteristics of soil quality. J. Soil Water Conserv., 50:243-248, 1995.

KLOSE, S. \& TABATABAI, M.A. Response of phosphomonoesterases in soils to chloroform fumigation. J. Plant Nutr. Soil., Sci., 165:429-434, 2002.

KNOEPP, J.D.; COLEMAN, D.C.; CROSSLEY, D.A. \& CLARK, J.S. Biological indices of soil quality: An ecosystem case study of their use. For. Ecol. Manag., 138:357-368, 2000.

LANDGRAF, D. \& KLOSE, S. Mobile and readily available C and $\mathrm{N}$ fractions and their relationship to microbial biomass and selected enzyme activities in a sandy soil under different management systems. J. Plant Nutr. Soil Sci., 165:9-16, 2002.

LAZARI, M.F. Nitrificação em solos sob plantações de eucaliptos com diferentes idades. Viçosa, MG, Universidade Federal de Viçosa, 2001. 50p. (Tese Mestrado)

LEIRÓS, M.C.; TRASAR-CEPEDA, C.; SEOANE, S. \& GILSOTRES, F. Biochemical properties of acid soils under climax vegetation (Atlantic oakwood) in an area of the European temperate-humid zone (Galicia, NW Spain): General parameters. Soil Biol. Biochem., 32:733-745, 2000.

LODHI, M.A.K. Inhibition of nitrifying bacteria, nitrification and mineralization in spoil soils as related to their sucessional stages. Bull. Torrey Bot. Club, 106:284-289, 1979 .

MABUHAY, J.A.; NAKAGOSHI, N. \& HORIKOSHI, T. Microbial biomass and abundance after forest fire in pine forests in Japan. Ecol. Res., 18:431-441, 2003.

MAGID, J.; TIESSEN, H. \& CONDRON, L.M. Dynamics of organic phosphorus in soils under natural and agricultural ecosystems. In: PICCOLO, A., ed. Humic substances in terrestrial ecosystems. Amsterdan, Elsevier, 1996. p.429-466.

MONDINI, C.; CONTIN, M.; LEITA, L. \& De NOBILI, M. Response of microbial biomass to air-drying and rewetting in soils and compost. Geoderma, 105:111-124, 2002.

MULLIN, J.B. \& RILEY, J.P. The spectrophotometric determination of nitrate in natural waters, with particular reference to sea-water. Anal. Chim. Acta, 12:464-480, 1955.

NANNIPIERI, P. The potential use of soil enzymes as indicators of productivity, sustainability and pollution. In: PANKHURST, C.E.; DOUBE, B.M.; GUPTA, V.V.S.R. \& GRACE, P.R., eds. Soil Biota: Management in sustainable farming systems. Melbourne, CSIRO, 1994. p.238-244, 1994.

NOVAIS, R.F.; SMYTH, T.J. \& BARROS, N.F. Fósforo em solo e planta em condições tropicais. Viçosa, MG, Universidade Federal de Viçosa, 1999. 399 p.

ODUM, E.P. The strategy of ecosystem development. Science, 164:262-270, 1969. 
OSAKI, F. Microbacias - Práticas de conservação do solo. Curitiba, 1994. 603p.

PAAVOLAINEN, L.; KITUNEN, V. \& SMOLANDER, A. Inhibition of nitrification in forest soil by monoterpenes. Plant Soil, 205:147-154, 1998.

POWLSON, D.S.; BROOKES, P.C \& CHRISTENSEN, B.T. Measurement of soil microbial biomass provides an early indication of changes in total organic matter due to straw incorporation. Soil Biol. Biochem., 19:159-164, 1987.

RETHEMEYER, J.; KRAMER, C.; GLEIXNER, G.; JOHN, B.; YAMASHITA, T.; FLESSA, H.; ANDERSEN, N.; NADEAU, M.J. \& GROOTES, P.M. Transformation of organic matter in agricultural soils: radiocarbon concentration versus soil depth. Geoderma, 128:94-105, 2005.

RICE E.L. \& PANCHOLY, S.K. Inhibition of nitrification by climax ecosystems. III. Inhibitors others than tannins. Am. J. Bot., 61:1095-1103, 1974.

RICE E.L. \& PANCHOLY, S.K. Inhibition of nitrification by climax ecosystems. II. Additional evidence and possible role of tannins. Am. J. Bot., 60:691-702, 1973.

RICE, E.L. \& PANCHOLY, S.K. Inhibition of nitrification by climax ecosystems. Am. J. Bot., 59:1033-1040, 1972.

ROBERTSON, G.P. Factors regulating nitrification in primary and secondary succession. Ecology, 63:1661-1573, 1982.

ROBERTSON, G.P. \& VITOUSEK, P.M. Nitrification potentials in primary and secondary sucession. Ecology, 62:376-386, 1981.

ROLDÁN, A.; SALINAS-GARCIA, J.R.; ALGUACIL, M.M.; DÍAZ, E \& CARAVACA, F. Soil enzyme activities suggest advantages of conservation tillage practices in sorghum cultivation under subtropical conditions. Geoderma, 129:178-185, 2005

ROSS, D.J.; SPEIR, T.W.; TATE, K.R. \& FELTHAM, C.W Burning in a New Zealand snow-tussock grassland: Effects on soil microbial biomass and nitrogen and phosphorus availability. New Zealand J. Ecol., 21:63-71, 1997.

SOLOMON, D.; LEHMAN, J.; MAMO, T.; FRITZSCHE, F. \& ZECH, W. Phosphorus forms and dynamics as influenced by land use changes in the sub-humid Ethiopian highlands. Geoderma, 105:21-48, 2002.

SORENSEN, L.H. Organic matter and microbial biomass in a soil incubated in the field for 20 years with ${ }^{14} \mathrm{C}$-labelled barley straw. Soil Biol. Biochem., 19:39-42, 1987.

SPARLING, G.P. Ratio of microbial biomass carbon to soil organic carbon as a sensitive indicator of changes in soil organic matter. Aust. J. Soil Res., 30:195-207, 1992.
STABEN, M.L.; BEZDICEK, D.F.; SMITH, J.L. \& FAUCI, M.F. Assessment of soil quality in conservation reserve program and wheat-fallow soils. Soil Sci. Soc. Am. J., 61:124-130, 1997.

STATSOFT, Inc. STATISTICA for Windows [Computer program manual]. Tulsa, StatSoft, 1995.

TABATABAI, M.A. Soil enzymes. In: WEAVER, R.W.; AUGLE, S; BOTTOMLY, P.J.; BEZDICEK, D.; SMITH, S.; TABATABAI, A. \& WOLLUM, A., eds. Methods of soil analysis. Part 2. Microbiological and biochemical properties. Madison, SSSA, 1994. v.5. p.775-833.

TAYLOR, J.P.; WILSON, B.; MILLS, M.S. \& BURNS, R.G. Comparison of microbial numbers and enzymatic activities in surface soils and subsoils using various techniques. Soil Biol. Biochem., 34:387-401, 2002.

TODD, R.L.; SWANK, W.T.; DOUGLASS, J.E.; KERR, P.C.; BROCKWAY, D.L. \& MONK, C.D. The relationship between nitrate concentration in southern Appalachian mountain streams and the terrestrial nitrifiers. Agroecosystems, 2:137-142, 1975.

TRASAR-CEPEDA, C.; LEIRÓS, C.; GIL-SOTRES, F. \& SEOANE, S. Towards a biochemical quality index for soils: An expression relating several biological and biochemical properties. Biol. Fert. Soils, 26:100-106, 1998.

TURNER, B.L.; HOPKINS, D.W.; HAYGARTH, P.M. \& OSTLE, N. $\beta$-Glucosidase activity in pasture soils. Appl. Soil Ecol., $20: 157-162,2002$

VANCE, E.D. Agricultural site productivity: Principles derived from long-term experiments and their implications for intensively managed forests. Forest Ecol. Manag., 138:369-396, 2000.

VANCE, E.D.; BROOKES, P.C. \& JENKINSON, D.S. An extraction method for measuring soil microbial biomass C. Soil Biol Biochem., 19:703-707, 1987.

VIANELLO, R.L. \& ALVES, A.R. Meteorologia básica e aplicações. Viçosa, MG, Universidade Federal de Viçosa, 1991. $449 \mathrm{p}$.

VOGT, D.J. \& EDMONDS, R.L. Potencial inhibition of nitrification in a Douglas-fir ecosystem. Bul. Ecol. Soc. Am., 58, 1977 (abstract).

WARDLE, D.A. Metodologia para quantificação da biomassa microbiana do solo. In: HUNGRIA, M. \& ARAUJO, R.S., eds. Manual de métodos empregados em estudos de microbiologia agrícola. Brasília, Embrapa, 1994. p.419-436.

WARDLE, D.A. \& GHANI, A. A critique of the microbial metabolic quotient $\left(q \mathrm{CO}_{2}\right)$ as a bioindicator of disturbance and ecosystem development. Soil Biol. Biochem., 27:16011610, 1995.

WARING, R.H. \& SCHLESINGER, W.H. Forest ecosystems: concepts and management. San Diego, Academic, 1985. 340 p. 